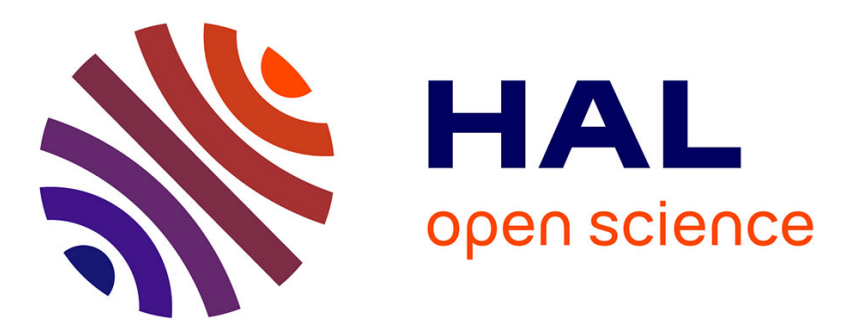

\title{
Complex numerical-experimental investigations of combustion in model high-speed combustor ducts
}

Mikhail Ivankin, Alexey Nikolaev, Vladimir Sabelnikov, Anna Shiryaeva, Vadim Talyzin, Vladimir Vlasenko

\section{- To cite this version:}

Mikhail Ivankin, Alexey Nikolaev, Vladimir Sabelnikov, Anna Shiryaeva, Vadim Talyzin, et al.. Complex numerical-experimental investigations of combustion in model high-speed combustor ducts. Acta Astronautica, 2019, 158, pp.425-437. 10.1016/j.actaastro.2018.11.046 . hal-02315623

\section{HAL Id: hal-02315623 \\ https://hal.science/hal-02315623}

Submitted on 14 Oct 2019

HAL is a multi-disciplinary open access archive for the deposit and dissemination of scientific research documents, whether they are published or not. The documents may come from teaching and research institutions in France or abroad, or from public or private research centers.
L'archive ouverte pluridisciplinaire HAL, est destinée au dépôt et à la diffusion de documents scientifiques de niveau recherche, publiés ou non, émanant des établissements d'enseignement et de recherche français ou étrangers, des laboratoires publics ou privés. 


\title{
Complex numerical-experimental investigations of combustion in model high-speed combustor ducts
}

\section{Mikhail Ivankin ${ }^{\mathrm{a}}$, Alexey Nikolaev, Vladimir Sabelnikov ${ }^{\mathrm{a}, \mathrm{b}}$, Anna Shiryaeva ${ }^{a}$, Vadim Talyzin ${ }^{\mathrm{a}}$ and Vladimir Vlasenko ${ }^{\mathrm{a} *}$}

${ }^{a}$ Central Aerohydrodynamic Institute named after Prof. N.E. Zhukovsky (TsAGI), 1 Zhukovsky street, Zhukovsky, Moscow Region, Russia, 140180, vlasenko.vv@yandex.ru

${ }^{\mathrm{b}}$ Office National d'Etudes et Recherches Aérospatiales (ONERA), Chemin de la Hunière, BP 80100, FR-91123

PALAISEAU cedex, France, vladimir.sabelnikov@onera.fr

* Corresponding Author

\begin{abstract}
Fast technologies for numerical simulation of high-speed flows in ducts, developed in TsAGI, are described. The examples are presented of the application of experimental data, obtained at T-131 wind tunnel, for validation of the developed numerical technologies: 1) validation of $2.5 \mathrm{D}$ and $3 \mathrm{D}$ calculations of flow in the elliptic combustor with hydrogen supersonic combustion that was studied within HEXAFLY-INT international project; 2) validation of 2D and 2.5D calculations of flow in high-speed model combustor duct with step-like expansion. Preparation of new series of experiments, oriented on validation of turbulent combustion models, is described.
\end{abstract}

Keywords: numerical simulation; experiment; validation; combustion; turbulence; high-speed combustor
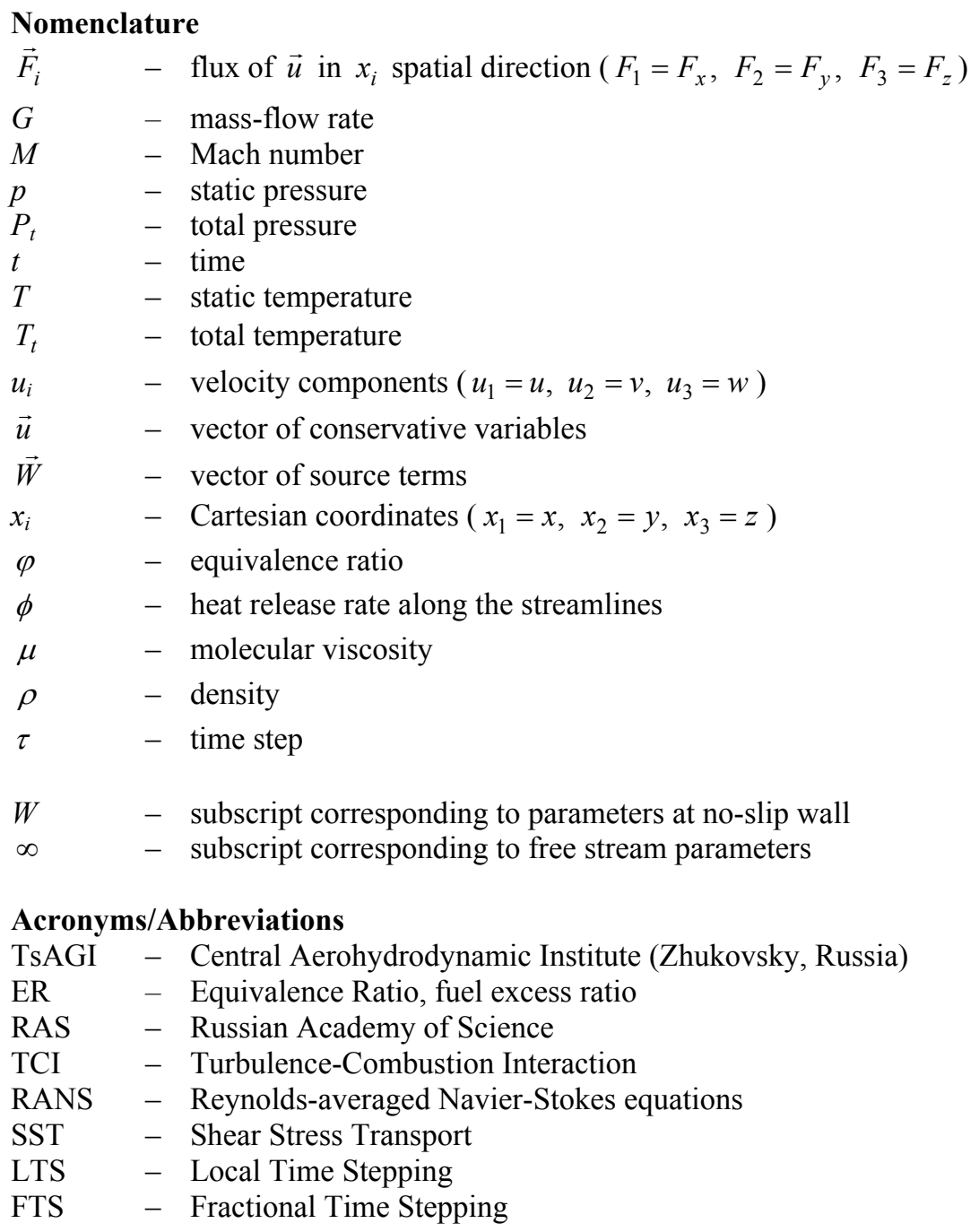


$\begin{array}{ll}\text { CPU } & - \text { Central Processor Unit } \\ \text { WT } & - \text { Wind Tunnel } \\ \text { EFTV } & - \text { Experimental Flight Test Vehicle } \\ \text { CIAM } & - \text { Central Institute of Aviation Motors (Moscow, Russia) } \\ \text { PDF } & - \text { Probability Density Function } \\ \text { CFD } & - \text { Computational Fluid Dynamics } \\ \text { ONERA } & - \text { Office National d'Etudes et Recherches Aérospatiales (France) } \\ \text { EBU } & - \text { Eddy Break-Up model } \\ \text { EDC } & - \text { Eddy Dissipation Concept } \\ \text { PaSR } & - \text { Partially Stirred Reactor }\end{array}$

\section{Introduction}

In the development of perspective aircraft, detailed investigations of the working process in high-speed ducts are necessary. The high cost of experiments, the inability to provide complete simulation of flight in ground conditions, the limited possibilities of using modern measuring equipment for detailed study of combustion processes in ducts at characteristic regimes lead to necessity to supplement the experiments with numerical simulation. However, modern possibilities of numerical simulation of high-speed turbulent flows with combustion are essentially limited by two factors: 1) huge computer costs in the calculation of unsteady $3 \mathrm{D}$ viscid gas flows with finite-rate reactions [1,2]; 2) low accuracy of the available physical models used to describe flows (models of turbulence, turbulent combustion and chemical kinetics) [3-5].

Section 2 of the current paper describes high-performance numerical simulation technologies developed in TsAGI to reduce the computer costs in the calculation of high-speed flows in ducts at the stage of preliminary design. These approaches allow the optimal distribution of computer resources to use more accurate physical flow models. The experimental validation of the developed numerical technologies becomes of great importance. At that, T-131 supersonic test rig (TsAGI) is used, which permits to performs experiments both for the model in the free flow (Mach numbers of the ambient flow are $M=5 \ldots 8)$ and in the connecting pipe regime $(M=2 \ldots 4)$. Section 3 of this paper describes the capabilities of T-131 test rig.

Sections 4 and 5 give examples of the using the experimental data obtained in the T-131 for validation of the developed numerical technologies: 1) validation of $2.5 \mathrm{D}$ and $3 \mathrm{D}$ flow calculations in an elliptical combustion chamber with supersonic hydrogen combustion, which was studied in the framework of an international project HEXAFLY-INT; 2) validation of $2 \mathrm{D}$ and $2.5 \mathrm{D}$ flow calculations in a high-speed model chamber with step expansion, which was considered within the joint project of the TsAGI-RAS Center for Computer Modeling.

In a number of cases, the numerical simulation does not permit to approach to the correct representation of experimental data. One of the most significant reasons for the discrepancy between the calculation and experiment is that there is no reliable description of the interaction between the turbulence and chemical kinetics (TCI). Section 6 of this article describes the results of studies on the description of TCI on the basis of flamelet approaches in combination with the probability density function method that have been performed in TsAGI. Recently, a laboratory for studies of turbulent flows with combustion has been created in TsAGI on the basis of the megagrant of the Ministry of Education and Science of the Russian Federation (contract No. 14.G39.31.0001). This project compares and adjusts various modern methods for describing TCI for high-speed ducts, and a series of detailed physical experiments specially designed for validation of the developed numerical technologies and physical models have been prepared at the T-131 test rig. Section 7 of this paper describes the geometry of the model combustion chamber chosen for these experiments, as well as results of the preliminary calculations of this chamber, which allowed to choose the fuel injection scheme.

\section{Numerical technologies for calculation of high-speed flows in ducts}

For a decade after 2000, TsAGI has developed a numerical technology for the accelerated calculation of nonstationary turbulent flows with nonequilibrium combustion for practical aerodynamics problems at the stage of preliminary design of power plants [6]. The calculations are performed in a 2D formulation based on the full unsteady Reynolds-averaged Navier-Stokes (unsteady RANS) equation system for a multicomponent compressible gas with finite-rate chemical reactions. The equation system is closed by the differential model of turbulence and by the kinetic scheme of gaseous fuel combustion in air. In this paper we describe the calculations performed using a turbulence model $q-\omega$ with a blending function (as in SST model), with taking into account the compressibility effects and with turbulence production correction [7]. In these calculations, a simplified model of chemical kinetics will be used, including the quasi-global reaction of hydrocarbon fuel oxidation to $\mathrm{CO}$ and $\mathrm{H}_{2} \mathrm{O}$ and 11 reactions between $\mathrm{H}, \mathrm{O}, \mathrm{OH}, \mathrm{H}_{2} \mathrm{O}, \mathrm{O}_{2}, \mathrm{H}_{2}, \mathrm{CO}, \mathrm{CO}_{2}$ with inert gas $\mathrm{N}_{2}$ [8] as well as model of the propane burning in the air 
[9]. The turbulence influence on combustion is not taken into account: the rate of chemical reactions is calculated using time-averaged values of the mixture parameters.

A second-order approximation numerical method is used for all variables. The method includes an explicit monotonic Godunov-Kolgan-Rodionov scheme for convective fluxes, an explicit modified central-difference approximation of the diffusion terms, and a locally implicit approximation of the source terms. Multi-block regular grids are used in the calculations.

To increase significantly the speed of unsteady flow calculation, while preserving the quality of their description, a methodology that was published in [10] is used. The methodology includes two main elements: 1) fractional timesteping technique (FTS); 2) the "wall law" boundary condition on non-slip solid walls.

The calculations are performed on highly non-uniform grids with thickening to solid walls. The maximum value of the time step required for explicit scheme stability in different grid cells can differ by several orders of magnitude. The FTS method allows to accelerate the calculation. For the first time, this approach was applied to calculations of flows with combustion in [11]. In TsAGI an original version of the FTS technique, described in [12], is used.

The calculation is performed with different time steps in different grid cells. In each cell, the time step is equal to $\tau=\tau_{\max } / 2^{k}$, where $\tau_{\max }$ is the maximum time step value in the whole computational domain, and the integer parameter $k$ is chosen to satisfy the local stability condition in the given cell. $2^{k}$ local steps are performed during one global time step in the current cell. The number of local time steps is different in different cells. But by the end of the global step, time increases by the same value $\tau_{\max }$ in all cells. In addition, during local time steps, processes in cells with different $\tau$ are synchronized by linear interpolation in time. As a result, the development of the unsteady flow is described correctly.

Depending on the ratio of the maximum and minimum time steps and on the number of cells with different time step values, the FTS technique can give acceleration from several times to several tens of times.

However, the FTS technique does not allow a calculation in an acceptable CPU time, if a flow with turbulent boundary layers is simulated. If an usual no-slip boundary condition is imposed on the solid walls, the grid must resolve the main elements of the near-wall turbulent boundary layer - the viscid sublayer (which defines the frictional force and the heat flux on the wall) and the buffer zone (where the largest turbulence production takes place). To resolve processes in a viscid sublayer, it's necessary to place 5-10 cells there. As a result, the near-wall cell size is about $0.01 \%$ of the boundary layer thickness. The stability condition for near-wall cells is so strong that the main part of the work is done in the depth of the boundary layers, and the FTS does not provide a real acceleration of the whole calculation.

To eliminate this problem, a "wall law" boundary condition is used on no-slip solid walls. This is an original version of the widely used method of wall functions (other versions of this approach are presented, for example, in [13-15]). It permits to use grids with substantially larger near-wall cells. A typical size of near-wall cells is about $1 \%$ of the boundary layer thickness. The "wall law" boundary condition assumes that the flow in a small neighborhood of a solid wall can be described by the same self-similar solution as the flow in a turbulent boundary layer on a flat plate. In particular, the dependence of the tangential velocity $V_{\tau}$ on the distance to the wall $y$ can be represented in a dimensionless form $\left(u^{+}=f\left(y^{+}\right) \quad\left(u^{+}=V_{\tau} / u_{\tau}, y^{+}=y / l_{\tau}, u_{\tau}=\sqrt{\tau_{W} / \rho_{W}}, l_{\tau}=v_{W} / u_{\tau}\right.\right.$, where $\tau$ is the tangential viscous stress, $\rho$ - density, $v$ - kinematic molecular viscosity, and the index " $W$ " corresponds to values on the wall). Substituting the parameters from the near-wall cell center into this dependence, one can find the tangential viscous stress on the wall $-\tau_{W}$. The diffusion flux of the turbulence parameter $q$ on the solid wall is assumed equal to $J_{W}(q) \approx 0.15 \tau_{W}$. The pressure on the wall is assumed to be equal to the pressure in the near-wall cell center: $p_{W} \approx p_{1}$. Using these conditions, one can determine the fluxes of all the parameters on the wall, which appear in the balance equations for the near-wall cell. An important original peculiarity of the "wall law" boundary condition is the using self-similar profiles of source terms for the turbulence parameters in the balance equations for the near-wall cell. Details of this boundary condition are given in [7].

To provide a possibility to perform calculations in a $2 \mathrm{D}$ formulation in ducts of an arbitrary shape, it was suggested in [16] to use the 2.5D flow approximation. In 2.5D approximation, the real 3D flow is replaced by a flow, which parameters are constant along the $z$ axis. This can be treated as a result of $3 \mathrm{D}$ flow averaging along $z$ axis. The calculations are performed in the $(x ; y)$ plane, but the variable width of the duct in the $z$ direction is taken into account. Let's represent 3D RANS equation system in the following form: 


$$
\frac{\partial \vec{u}}{\partial t}+\frac{\partial \vec{F}_{x}}{\partial x}+\frac{\partial \vec{F}_{y}}{\partial y}+\frac{\partial \vec{F}_{z}}{\partial z}=\vec{W}
$$

Then $2.5 \mathrm{D}$ analogue of 3D flow will be described by following equation system:

$$
\frac{\partial}{\partial t}\left(\vec{u} h_{z}\right)+\frac{\partial}{\partial x}\left(\vec{F}_{x} h_{z}\right)+\frac{\partial}{\partial y}\left(\vec{F}_{y} h_{z}\right)+\left(\vec{F}_{x}^{-} \frac{\partial z_{\min }}{\partial x}-\vec{F}_{x}^{+} \frac{\partial z_{\max }}{\partial x}+\vec{F}_{y}^{-} \frac{\partial z_{\min }}{\partial y}-\vec{F}_{y}^{+} \frac{\partial z_{\max }}{\partial y}+\vec{F}_{z}^{+}-\vec{F}_{z}^{-}\right)=\vec{W} h_{z} .
$$

Here $z_{\max }(x, y), z_{\min }(x, y)$ are z-coordinates of duct walls, $h_{z}(x, y)=z_{\max }-z_{\min }, \vec{F}_{x}^{+}, \vec{F}_{y}^{+}, \vec{F}_{z}^{+}$are the values of the flux vectors at duct wall with coordinate $z_{\max }, \vec{F}_{x}^{-}, \vec{F}_{y}^{-}, \vec{F}_{z}^{-}$are the values of these vectors at the duct wall with coordinate $z_{\min }$. The fluxes $\vec{F}_{i}^{+}$and $\vec{F}_{i}^{-}$are calculated with the use of a special procedure. The wall pressure is taken to be equal to the pressure averaged along $z$. Viscid forces are projected on local direction of the unit vector normal to the duct surface and interpolated between the upper and lower walls of the duct. Details are given in [16].

\section{Possibilities of experimental studies in T-131 wind tunnel}

For investigations of high-speed aircraft engines in TsAGI, there is a unique high-speed wind tunnel (WT) T-131 (see detailed information at http://tsagi.com/experimental base/t-131/). This is a facility, which consists of two test rigs now (Fig. 1).
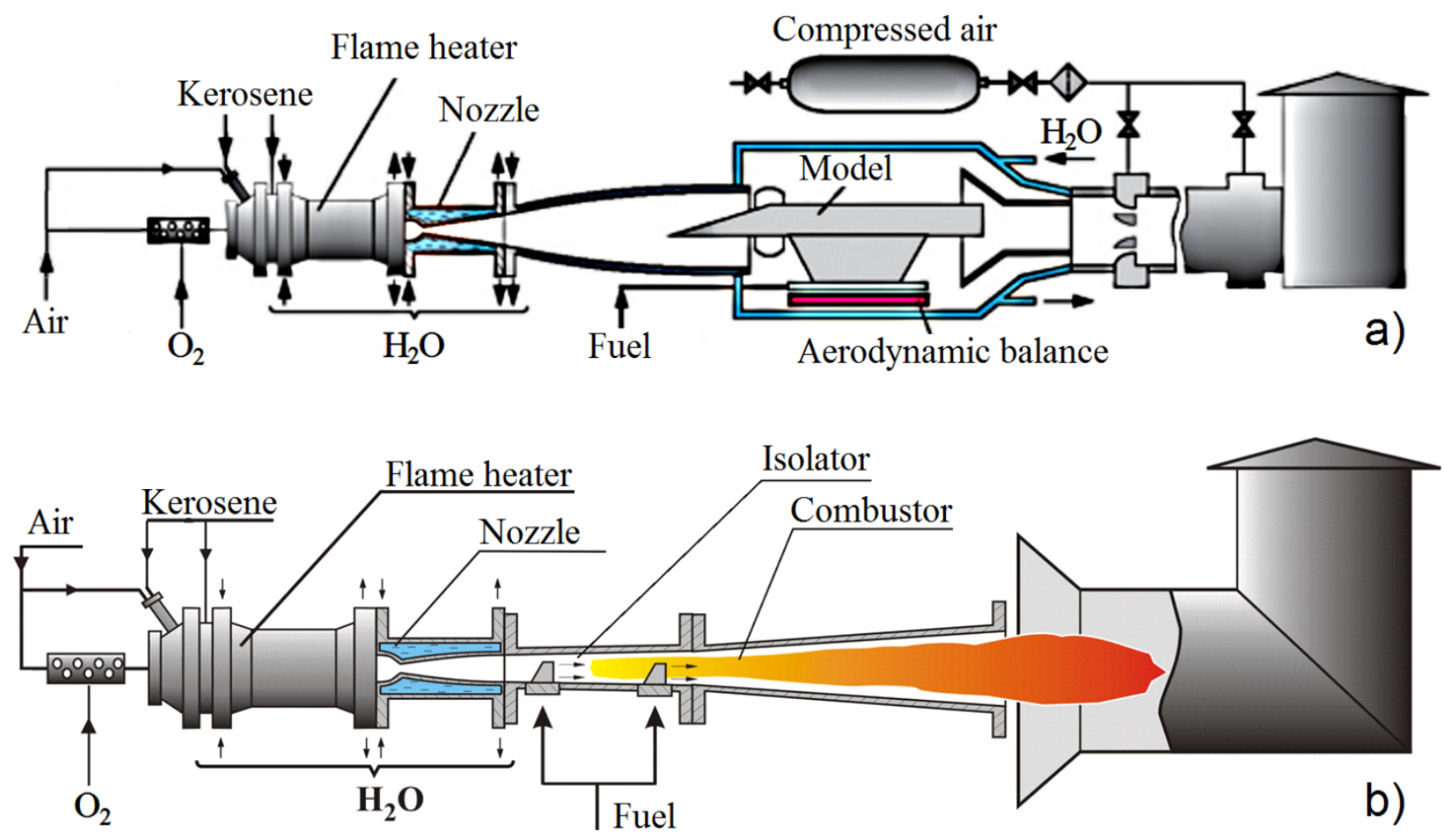

Fig. 1. Scheme of the T-131V test rig with installed model combustion chamber

T-131B test rig allows testing high-speed ramjet modules in free flow with a Mach number $\mathrm{M}=5 \ldots 8$ with the representation of flight conditions at an altitude up to $35 \mathrm{~km}$. The test part of the test rig has a diameter of $1.2 \mathrm{~m}$, a length of $2.3 \mathrm{~m}$, a nozzle exit diameter is $0.4 \mathrm{~m}$. The test rig allows tests in a regime of external flow around a model up to $2 \mathrm{~m}$ in length. Examples of tested high-speed ramjet modules are shown in Fig. 2, a.

$\mathrm{T}-131 \mathrm{~V}$ test rig allows to test the models of high-speed ramjet combustion chambers and their elements on the connecting pipe. The tested model is joined to replaceable nozzles of the test rig that has an entrance cross-section 
diameter of $0.1 \mathrm{~m}$ or $0.148 \mathrm{~m}$. The exit section of the nozzle is rectangular, with dimensions of $0.03 \mathrm{~m} \times 0.1 \mathrm{~m}$; $0.04 \mathrm{~m} \times 0.1 \mathrm{~m}$ or $0.1 \mathrm{~m} \times 0.1 \mathrm{~m}$. Choice of the nozzle critical section area provides the Mach numbers of the flow at the entrance into the investigated model in the range $M=2 \ldots 4$. The model length can be up to $3 \mathrm{~m}$. Figure 2,b shows photos of the T-131V test rig with mounted model combustion chamber and with test rig systems, which provide its work, including high-pressure air supply pipes, pipes that supply water to the cooling systems, pipes of fuel supply to injectors, as well as drainage pipes that go to the static pressure sensors installed on the model walls.

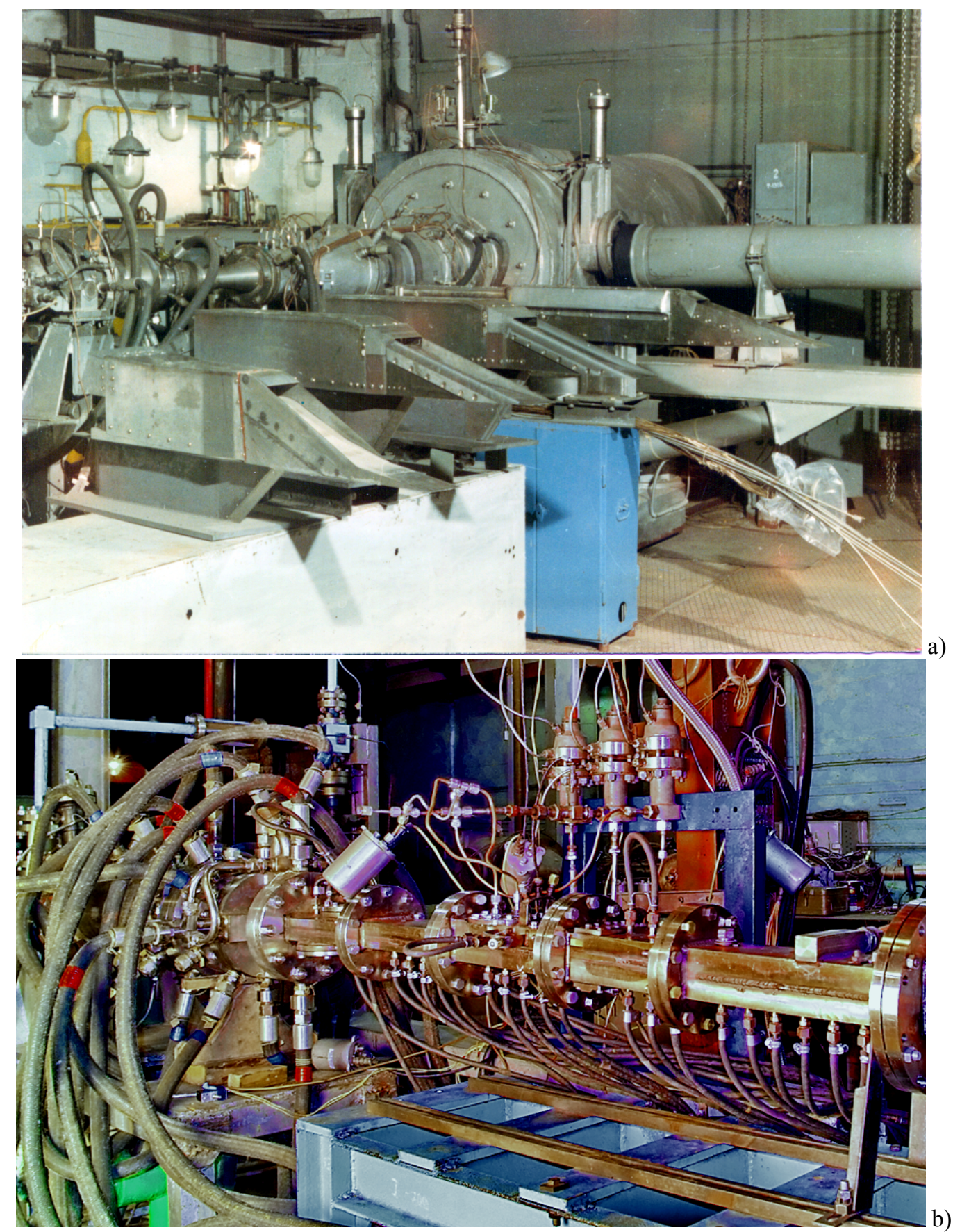

Fig. 2. Photos of T-131 wind tunnel: a) T-131B test rig and high-speed ramjet modules tested at this test rig; b) T-131V test rig with mounted model combustion chamber and test rig systems that provide its work 
The air flow in both test rigs is heated by a fire heater and enriched with oxygen to a composition close to the air composition. It permits to create a flow with a total pressure up to $11 \mathrm{MPa}$ and a total temperature up to $2350 \mathrm{~K}$. This provides the experimental conditions, which are maximally close to the real conditions of high-speed flight.

$\mathrm{T}-131$ test rig is intended to investigate:

- Combustion chambers of high-speed ramjets and their elements;

- Combustion processes in high-speed combustors;

- Mixing and combustion processes in supersonic flows;

- Combustion processes in the bottom zone of the aircraft;

- Structural materials.

There is necessary infrastructure for performing tests with combustion in combustion chambers, as well as determining the thrust characteristics of propulsion systems. The test rigs are equipped with a measuring and computing system, television equipment, photo and video equipment, Toepler's device for shadow photography. During the "hot" tests, it is possible to measure pressure distributions along the duct walls of the model and to measure the temperature of the outer surface of these walls.

T-131 wind tunnel systems allow tests with supplying the hydrogen fuel (mass flow rate up to $0.2 \mathrm{~kg} / \mathrm{s}$ ), liquid hydrocarbon fuels, products of pyrolysis and conversion of hydrocarbon fuels (mass flow rate up to $0.5 \mathrm{~kg} / \mathrm{s}$ ). During the experiments, it is possible to use various combustion ignition systems - from forced ignition by cartridge-igniter to the organization of conditions that ensure fuel-air mixture self-ignition due to gas dynamic or mechanical duct throttling.

Studies of high-speed ramjet and their combustion chambers have been performed in T-131 wind tunnel for over 30 years. During this period, a wide variety of devices were tested - from modules and combustion chambers for high-speed ramjets [17-20] and their elements to gasdynamic combustion stabilizers [21], detonation initiators [22] and pulse detonation tubes [23]. High-speed profiled combustion chambers with different degrees of expansion, with different methods of fuel delivery organization were investigated. A wide range of gaseous, liquid and solid fuels was considered.

\section{Validation of 2.5D and 3D calculations of flow in HEXAFLY-INT combustor}

\subsection{Preliminary numerical analysis of flow in the HEXAFLY-INT combustor}

In the framework of HEXAFLY-INT European project (7th Framework Program, Contract No. ACP3-GA-2014620327) [24,25], the Experimental Flight Test Vehicle (EFTV) is considered. It is a model-demonstrator of a highspeed civil aircraft designed for a cruising flight with Mach number values $M=6 \ldots 8$. The EFTV power plant flowpath model was manufactured in the CIAM and tested in TsAGI T-131 test rig on the connecting pipe. The EFTV flowpath has elliptical cross-sections. There are two zones of fuel supply. In the first zone, hydrogen is injected vertically, normally to the flow, and in the second zone - in the horizontal plane. The necessity to perform parametric investigations of such power plant has led to the creation of a $2.5 \mathrm{D}$ approximation for the description of $3 \mathrm{D}$ flows in ducts [16].

The geometry of the EFTV combustion chamber model can be seen in Fig.3. At the entrance into the chamber, there is an air flow heated by the firing heater and enriched with oxygen so that the mass fraction of oxygen is the same as in air. The average Mach number at the entrance to the chamber varies within $M \approx 2.45 \ldots 3.1$. The temperature of the inviscid core at the entrance is greater than $1000 \mathrm{~K}$, but it is only $163 \mathrm{~K}$ in injected hydrogen jets.

To determine the initial profile of the parameters at the entrance to the EFTV combustion chamber model, 2.5D flow calculations have performed in the transition nozzle that connects the fire heater of the T-131 test rig with the combustion chamber model. For this series of experiments, a short Laval nozzle with a rapid change in area has been considered. $2.5 \mathrm{D}$ calculations have shown that, in this case, estimations of the parameters at the entrance into the chamber, which are based on the quasi-1D theory and on the assumption about the equilibrium gas composition, are unsuitable, since there are significant losses in the transition nozzle due to oblique shock waves, boundary layers on the nozzle walls and finite-rate chemical processes in the nozzle.

Preliminary 3D flow calculations in the EFTV combustion chamber without combustion have shown that the cross-sections of the fuel jets are elongated in the vertical direction. Thus, the flow parameters vary along the $y$-axis weaker than along the $z$-axis. Therefore, $2.5 \mathrm{D}$ flow calculations in the combustion chamber model have been performed in the $(x, z)$ plane instead of $(x ; y)$ plane. Figure 3,a shows typical temperature fields in the stationary combustion regime. In hydrogen jet from the semi-struts of the first zone, firstly, there is only a weak heat release at the outer boundary of the jets due to the low temperature of hydrogen. But before the blunt front edge of the central full-strut in the second zone, an intense shock wave is generated. Its interaction with the duct walls leads to separation of the boundary layer and to formation of Mach disks. Zones with reduced speed, increased vorticity and 
temperature are generated; it promotes hydrogen-air mixing and combustion. That is why downstream from the central full-strut, intensive heat release begins in all hydrogen jets. The end of heat release is associated with the beginning of the part with the fast growth of the duct height.
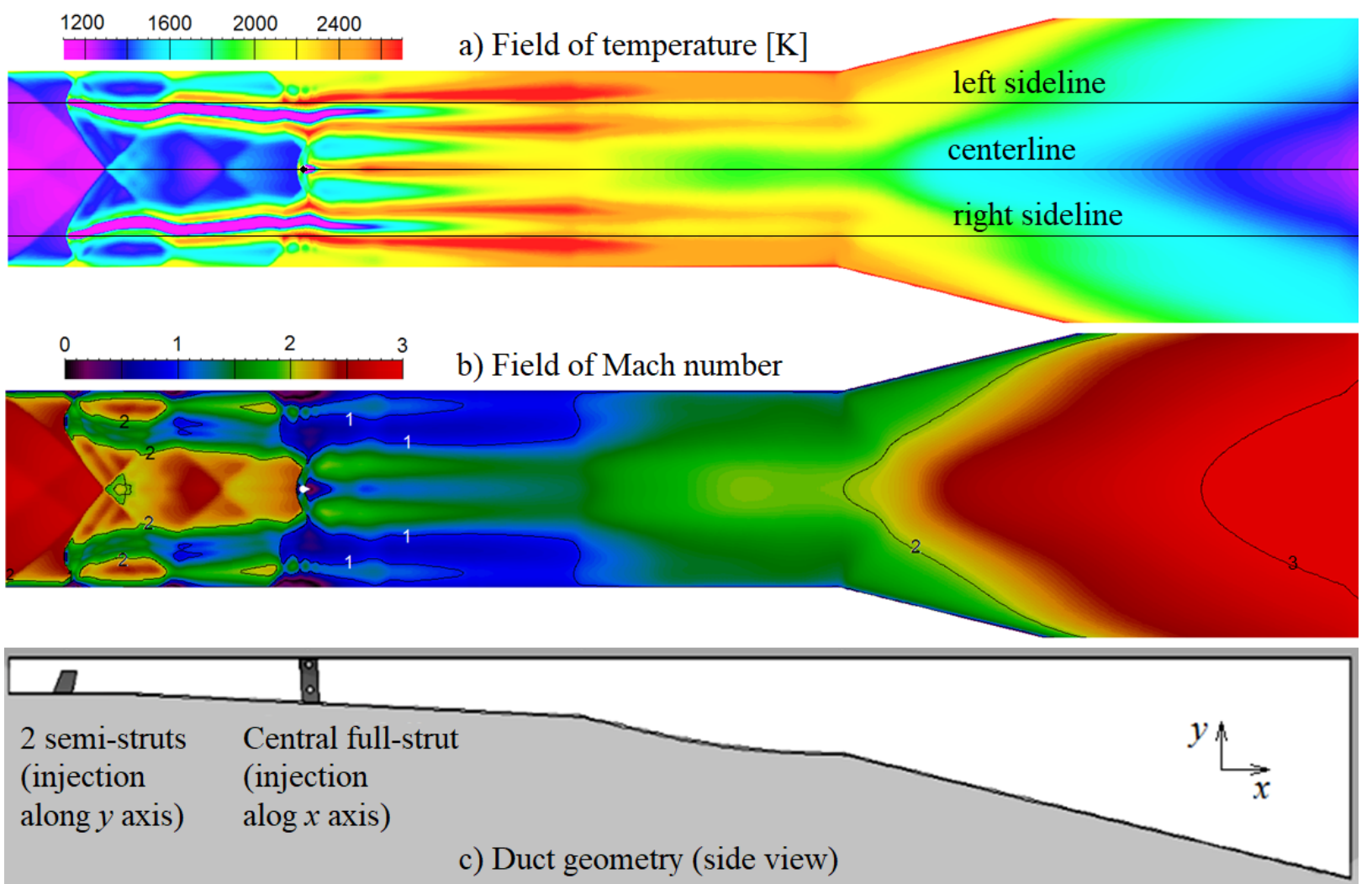

Fig. 3. Geometry of the EFTV flow passage and typical temperature fields:

$\mathrm{a}, \mathrm{b}$ - top view and flowfields in the $(x, z)$ plane; $\mathrm{c}$ - side view. The duct is cropped from the right in upper picture.

The arrows show the corresponding sections in the top and side views

Preliminary 2.5D calculations of flow in the EFTV combustion chamber described in [16] have permitted to determine the optimal ratio of hydrogen consumption injected in the first and the second fuel supply zones. The calculations have been performed for the following variants: 1) $10 \%-10 \%-80 \%(10 \%$ of hydrogen mass flow rate from the semi-struts of the first zone, $80 \%$ of the central full-strut); 2) $20 \%-20 \%-60 \%$; 3) $25 \%-25 \%-50 \%$; 4) $30 \%$ $30 \%-40 \%$; 5) $33 \%-33 \%-34 \%$; 6) 40\%-40\%-20\%; 7) 50\%-50\%-0\%. For each variant, the longitudinal force applied to the chamber walls has been determined. The best thrust characteristics have been obtained for the variant 4). Analysis of the calculated flowfields has permitted to explain this result. The core of the outer jets remains too cold over the whole length of the combustion chamber in the variants 6) and 7), and the core of the central jet - in the variants 1) and 2). A compromise is achieved in the variants 3)-5). In the variant 3), the most uniform heat distribution along the duct cross-section is achieved. In the variant 4), more heat is released in the central jet. In the variant 4), the highest fuel combustion efficiency and the maximum thrust of the chamber are reached.

For three most attractive regimes, 3D calculations have been performed, which require an order of magnitude more time and computer memory. They confirmed that the maximum thrust is achieved near $30 \%-30 \%-40 \%$. At that, the combustion efficiency and thrust in $3 \mathrm{D}$ calculations is by $5 \%$ lower, because, in the $2.5 \mathrm{D}$ approximation, the fuel jets are in one plane and "press" each other. It increases the heat release rate. Figure 4,a summarizes the results of the determination of the EFTV combustion chamber characteristics obtained in $2.5 \mathrm{D}$ and $3 \mathrm{D}$ calculations. The horizontal axis represents the fuel consumption proportion supplied from the central full-strut holes. Blue color shows the obtained values of the chamber thrust, and the red color shows the combustion efficiency values. This graph demonstrates the correlation between the thrust and the heat release value in the duct. Figure 4,b compares the pressure distributions along the duct midline obtained in $3 \mathrm{D}$ and $2.5 \mathrm{D}$ calculations with a fuel supply scheme of $30 \%-30 \%-40 \%$. The agreement of the results is good if one takes into account that the $3 \mathrm{D}$ calculation graph is obtained using the local pressure values and, in the $2.5 \mathrm{D}$ calculation, the pressure is averaged over $y$. 


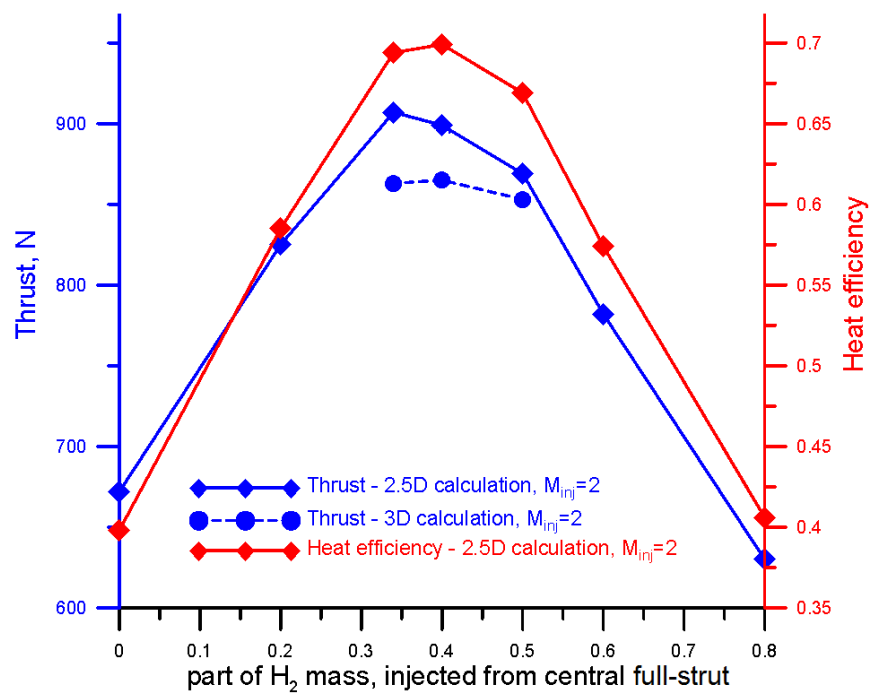

a)

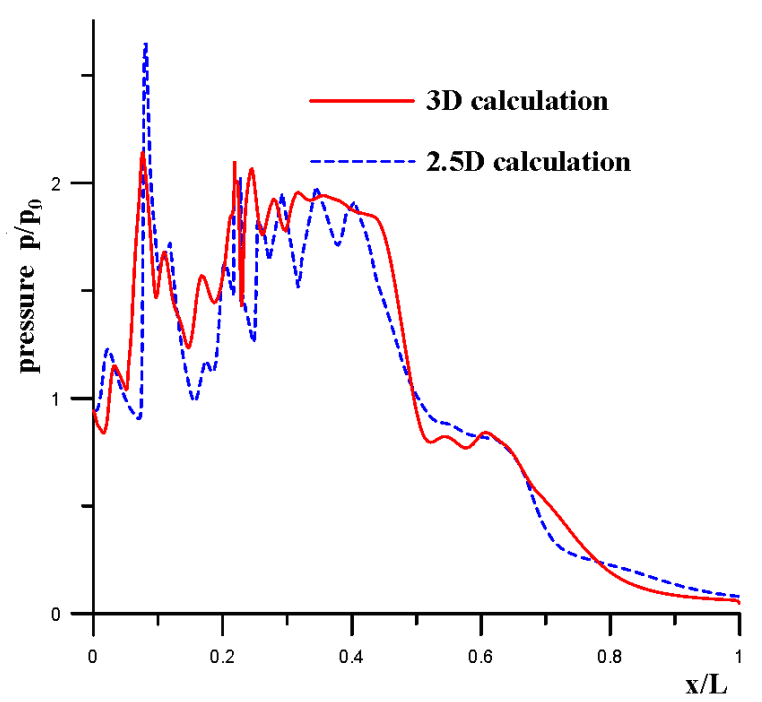

b)

Fig. 4. Comparison of 2.5D and 3D calculations of EFTV combustion chamber:

a) the dependence of the combustion chamber characteristics on the choice of the fuel supply scheme;

b) the pressure distribution along the duct centerline with a fuel supply scheme of $30 \%-30 \%-40 \%$

\subsection{Experimental validation of $2.5 \mathrm{D}$ approach}

After experiments in T-131B wind tunnel of TsAGI, validation of the used numerical technology was performed. For this purpose, experimental runs were simulated in calculations. Calculated pressure distributions along the chamber walls were compared with experiments.

Three series of experiments were performed. These series corresponded to flight Mach number $M_{\infty}=7$, $M_{\infty}=7.4$ and $M_{\infty}=6$. At the flight regime $M_{\infty}=7$, the flow parameters at EFTV entrance are $M \approx 2.6$, $P_{\mathrm{t}} \approx 14 \mathrm{~atm}$, air mass-flow $G \approx 1.55 \mathrm{~kg} / \mathrm{sec}$. At the flight regime $M_{\infty}=7.4$, inflow parameters are $M \approx 3$, $P_{\mathrm{t}} \approx 12 \mathrm{~atm}, G \approx 0.7 \mathrm{~kg} / \mathrm{sec}$, and for the regime $M_{\infty}=6$ inflow parameters are $M \approx 2.3, P_{\mathrm{t}} \approx 10 \mathrm{~atm}, G \approx 1.6 \mathrm{~kg} / \mathrm{sec}$. In addition to inflow regime, experimental runs differed by the hydrogen mass-flow rate (i.e. by equivalence ratio $\varphi$ ). Central full-strut was used as injector only in part of runs. In one experimental run it was destroyed by flame, and in following runs the hydrogen mass flow rate was equidistributed between the semi-struts. In part of runs, imitator of central full-strut was mounted at its place, but hydrogen was injected only from the semi-struts.

In Fig. 5, an example of the static pressure longitudinal distributions is shown. These distributions were obtained for the same flow regime as in Fig.3. Upper picture shows the distributions along central line that is shown in Fig.3, and the lower picture shows distributions along lateral lines, which are also shown in Fig.3. Calculated data along two lateral lines coincide. Experimental data, obtained along sidelines, are shown by different triangle markers. Difference between markers, corresponding to the same longitudinal coordinates, characterizes the experimental data scatter. Blue curves correspond to cold flow without fuel injection, red curves - to hot flow with hydrogen injection and combustion.

For this flow regime, 3D calculation of cold flow without fuel injection has also been performed (on comparable grid). Results of this calculation are also shown in Fig.5; they differ from 2.5D calculation data because of difference in local structure of 3D flow and $y$-averaged flow parameters, which are simulated in 2.5D flow, and also because of errors that are intrinsic to 2.5D approximation (see Section 8 of this paper). Nevertheless, discrepancy of 3D calculation data and experiment is not better than the errors of $2.5 \mathrm{D}$ calculation. It is characteristic for modern stateof-the-art of high-speed combustor flow simulations. Modern models of turbulence and combustion still cannot provide adequate description of real flows. From this viewpoint, $2.5 \mathrm{D}$ approximation is very good way to estimate the real flow characteristics, if one takes into account that computational cost of $2.5 \mathrm{D}$ approach are lower by an order than computational cost of $3 \mathrm{D}$ calculations. 

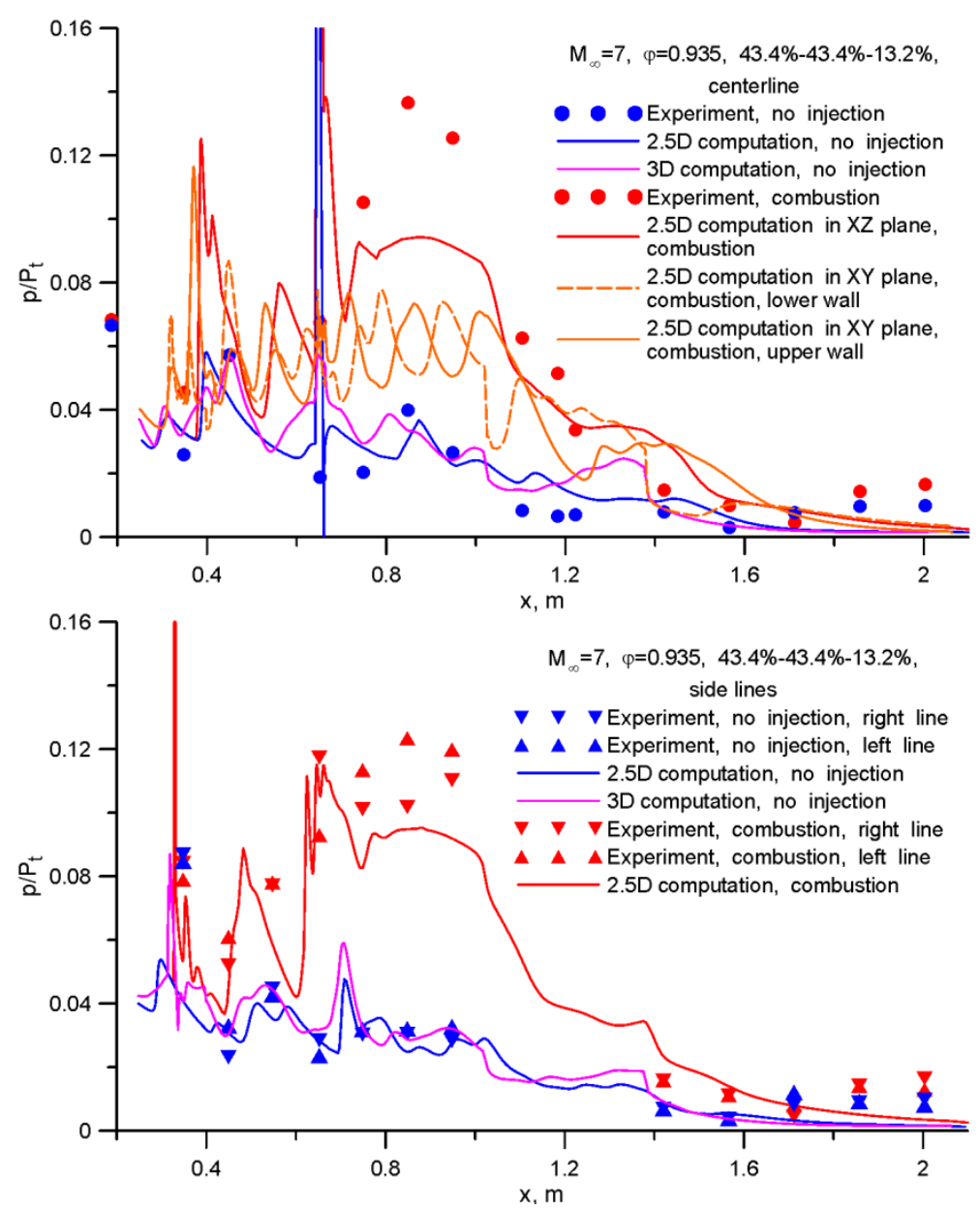

Fig. 5. Longitudinal distributions of pressure for the same run as in Fig.3 $\left(M_{\infty}=7, \varphi=0.935\right)$

With the exception of the interval $0.85<x<1.0 \mathrm{~m}$ at the duct centerline, the discrepancy between $2.5 \mathrm{D}$ calculation in $(x, z)$ plane and the experiment is close to experimental data scatter. It is also necessary to take into account that the experimental data are local, whereas data of $2.5 \mathrm{D}$ calculations are averaged along vertical lines passing through the current point of $(x, z)$ plane. Averaging should smooth the peaks in pressure distribution, and one may see this effect in Fig.5.

For all considered regimes, the same quality of agreement between $2.5 \mathrm{D}$ calculations and the experiment is obtained. Figure 6,a,b demonstrates another examples, obtained for $M_{\infty}=7.4$, and Figure 6,c,d - for $M_{\infty}=6$. These pictures have the same specific features as in Fig.5. It is especially important that very different flow regimes were considered in calculations- from intensive combustion in Fig.5 and in Fig.6,c,d to practically cold flow in Fig.6,a. In all cases $2.5 \mathrm{D}$ calculations reproduce correctly the qualitative features of pressure distributions.

In simulation of flow regimes, corresponding to the flight Mach number $M_{\infty}=6,2.5 \mathrm{D}$ calculations did not immediately yield positive results. For some regimes the combustion practically did not developed in calculation (see orange curves in the plots for the regime $\varphi=0.763$ - Fig.6,d). But in the experiment intensive combustion was observed. It means that in real 3D flow picture the sufficient-for-combustion conditions arise locally, but in $y$ averaged field of 2.5D flow the conditions are not sufficient for the flame ignition.

In those regimes the mixture was too lean for self-ignition. But in the regime $\varphi=1.01$ the mixture was close to stoichiometry, the self-igntion took place, and intensive combustion appeared - see Figures 6,c. Pressure distributions, qualitatively similar to experimental data, were obtained. After that an attempt to start calculation for the regime $\varphi=0.763$ from the converged field for the regime $\varphi=1.01$. It allowed to get stationary solution with developed combustion and to obtain pressure distributions that were much more close to experimental data (see red lines in Fig.6,d).

Hysteresis phenomena (dependence of the stationary state upon pre-history) are characteristic to flows with combustion. The most well-know example is solution of task about well-stirred reactor [26-27]. 


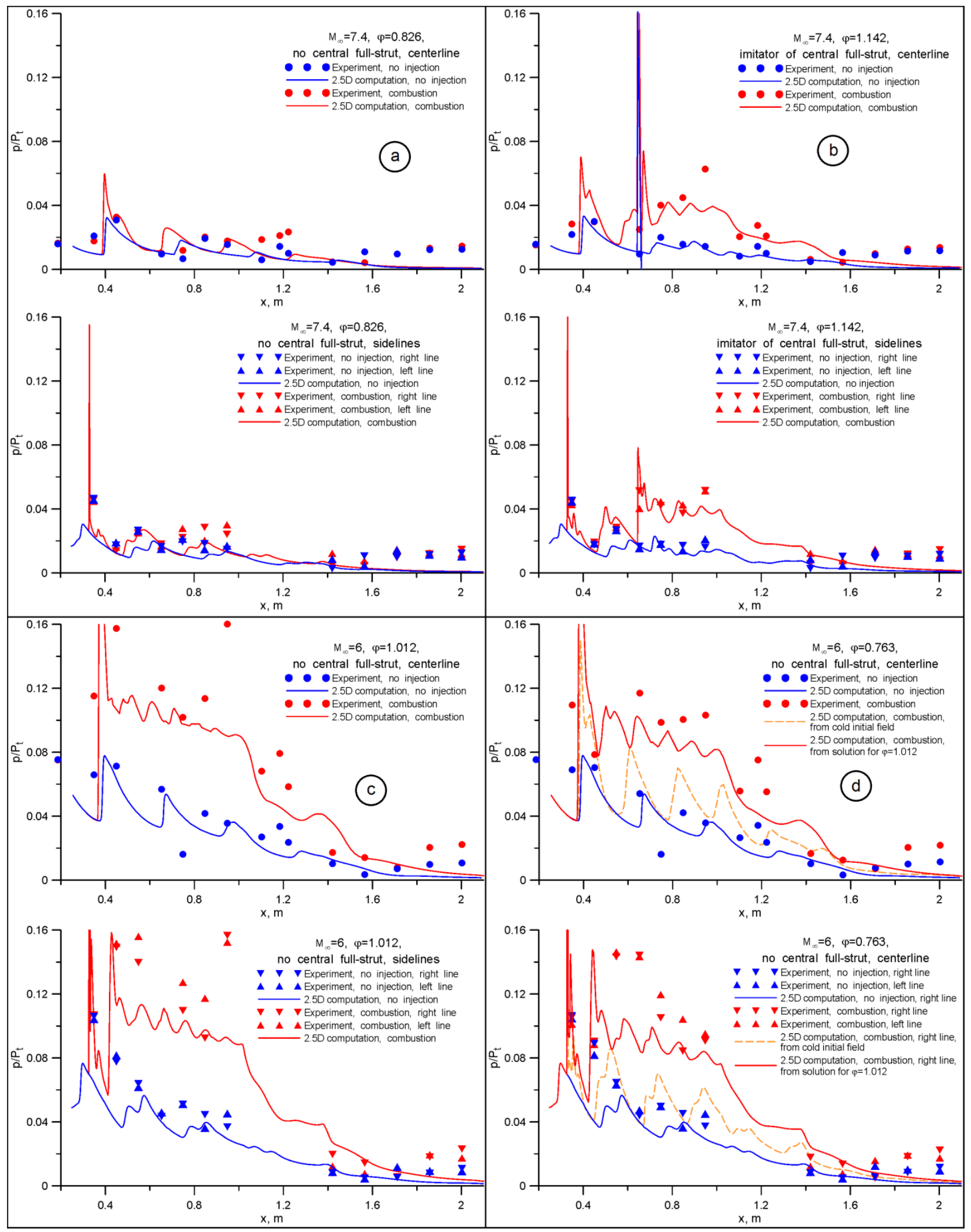

Fig. 6. Longitudinal distributions of pressure for the experimental runs, corresponding to $M_{\infty}=7.4(\mathrm{a}-\varphi=0.826, \mathrm{~b}-\varphi=1.142)$ and to $M_{\infty}=6(\mathrm{c}-\varphi=1.012, \mathrm{~d}-\varphi=0.763)$ 
In some regimes, longitudinal oscillations of combustion zone appeared. These oscillations produced essential variation of the longitudinal force, applied to duct walls. The flame periodically propagated upstream and reached the duct entrance. It was a serious problem, because the calculations were performed with local time stepping (LTS, see [12]) to accelerate convergence to stationary state. If stationary state is not reached, then the flowfields, obtained in calculation with LTS, do not satisfy to conservation laws. Moreover, when the flame reached the duct entrance, the flow near the entrance became subsonic throughout, and the entrance boundary condition with given flow parameters began to work incorrectly, leading to violation of given mass-flow rate. So, for the regime $M_{\infty}=7$, $\varphi=1.101$ the calculation with fractional time stepping (FTS, see the Section 2 above) was performed. The FTS technology allows to describe unsteady processes correctly. To impose the entrance boundary condition correctly, the entrance section was moved into supersonic part of the connecting pipe. In computation, flame oscillations finally became periodic. Structure of oscillations during one period appeared to be very complex. However, detailed analysis has shown that the mechanism of oscillations is close to one considered in [6, 28]. The main reason of the oscillations is periodical coming of fuel into the separation zones at the duct walls that leads to temporary combustion inside the separation bubbles with growth of their size and with essential variation of the flow structure.

After that the instant pressure distributions in some moments of calculation, as well as time-averaged pressure distributions, have been compared with experimental data. Scatter between these curves was found to be close to the experimental data scatter, and agreement of calculation with experiment was of the same quality as in Fig. 5-6.

Totally, 19 regimes have been considered, and satisfactory agreement of calculated pressure distributions with experiment is obtained. Therefore, 2.5D method allows to predict the most important physical features of flow and predicts loads on duct walls with engineering accuracy, that is enough for multiple parametric calculations at the stage of engine preliminary design or at the stage of experiment preparation.

\section{Study of flow in high-speed combustor with step}

As part of the project of the TsAGI-RAS Center for Computer Simulation named after Academician O.M.Belotserkovsky, flows in a model high-speed combustion chamber with a step on hydrocarbon fuel have been investigated. Such flows were studied experimentally for many years in T-131V test rig (TsAGI) in the connecting pipe system. The combustion chamber is a duct with a step that consists of a short part with an expansion angle of $0.5^{\circ}$ ("isolator") and a long constant-area part (Figure 7). All cross-sections of the duct have a rectangular shape. Fuel is supplied through the holes on the side walls of the semi-struts placed at the end of the isolator. The fuel jets are injected sidewise. In 2D calculations, injection has been simulated by adding sources of mass, energy, fuel mass and turbulence parameters to the balance equations in those grid cells that are placed at injection hole locations.

The flow regime with the total parameters $P_{t} \approx 1.9 \mathrm{MPa}, T_{t} \approx 1100 \mathrm{~K}$ and the heated air mass flow $G_{\text {air }} \approx 2.45$ $\mathrm{kg} / \mathrm{sec}$ was considered. The fuel consumption corresponded to the fuel excess ratio $\varphi \approx 0.75$. The Mach number at the entrance into the combustion chamber is $M \approx 2.5$. To initiate the combustion in the experiment, a pneumothrottle is used: during a short time, cross jets of compressed air are injected from the holes located at the lower wall of the duct near the exit from the chamber. Because of the duct choking, separation zones in the flow are generated where ignition occurs. A prolonged nonstationary process begins, which can result in the stabilization of combustion or in its blowout. Attempts to correctly describe this process have resulted in the development of the numerical technology, presented in the Section 2.

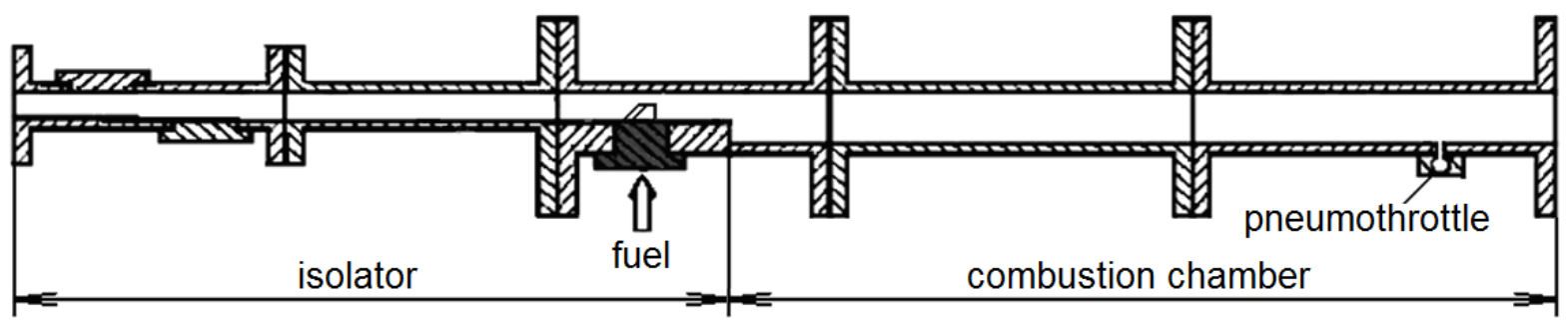

Fig. 7. Geometry of model combustor with step

The static temperature in the inviscid core of the flow at the duct entrance is close to $530 \mathrm{~K}$. In the experiment, the combustion has been successfully created using a pneumothrottle. In the calculations, blowing of compressed air jet from the duct walls was simulated directly, but the combustion has not occured. It has been found that, in order to ignite the combustion in the calculation, it is necessary to use a chemical kinetics model with taking into account the two-stage ignition of hydrocarbon fuel at low temperatures. For this purpose, a method of switching the constants in 
the quasi-global reaction of hydrocarbon fuel decomposition to $\mathrm{CO}$ and $\mathrm{H}_{2} \mathrm{O}$, which was proposed in [9], has been used. At that, quasiperiodic oscillations of the combustion zone arise in the calculation. Analysis of flowfields has allowed to determine the physical mechanism of these oscillations.

Figure 8 shows the flow development during one oscillation cycle. There are the fields of temperature $T$ (left) and the fields of the decimal logarithm of heat release rate $\phi$ [28] (right), which is determined by the formula

$$
\phi(x, y)=\frac{\sum W_{k} Q_{k}}{\rho|\vec{V}|}
$$

where $W_{k}$ is the rate of $k$-th chemical reaction $\left[\mathrm{mole} \cdot \mathrm{m}^{-3} \cdot \mathrm{sec}^{-1}\right], Q_{k}$ is the heat effect of this reaction $\left[\mathrm{J} \cdot \mathrm{mole}{ }^{-1}\right]$, $\rho$ - density, a $|\vec{V}|$ - gas velocity.
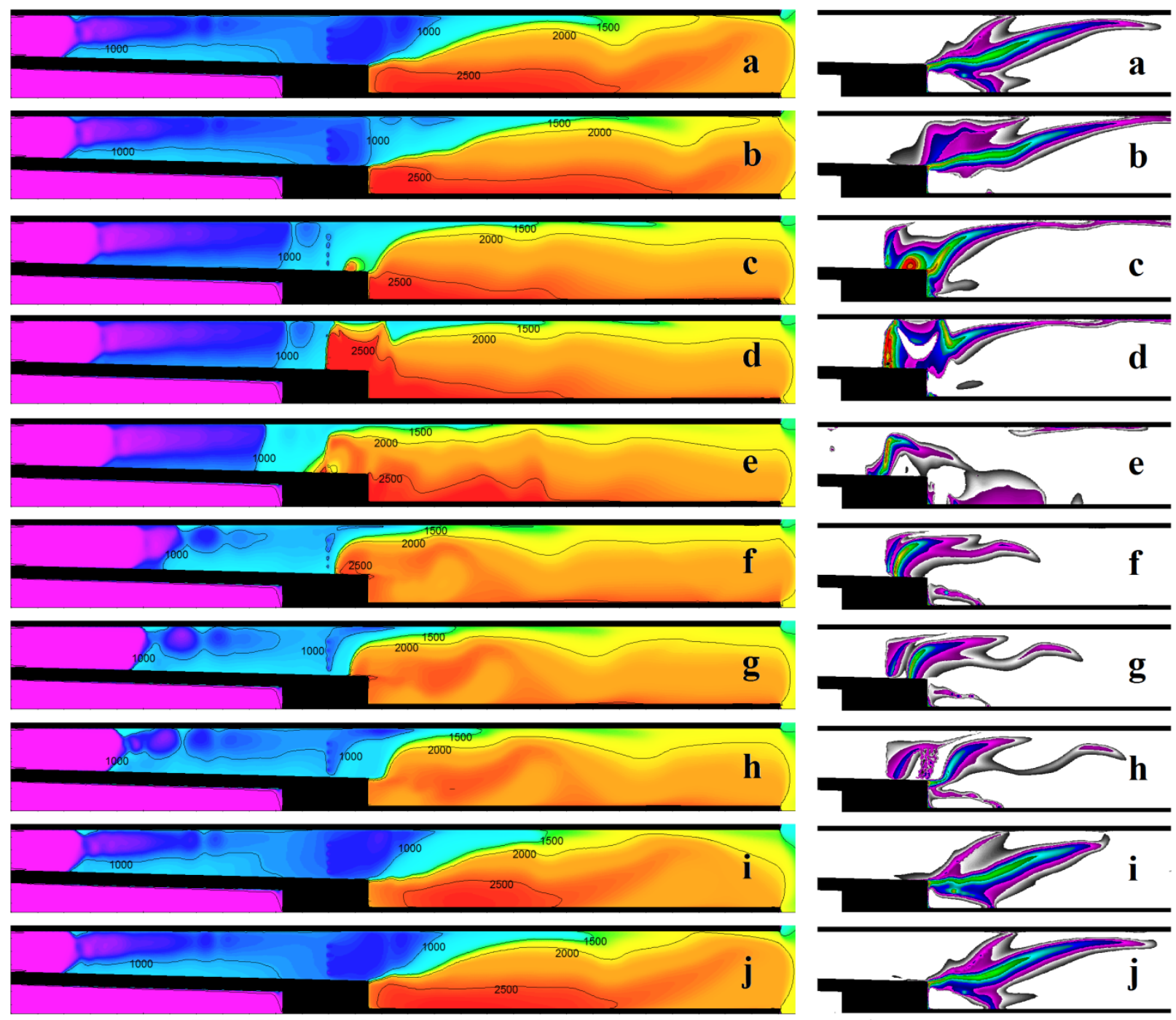

$\mathrm{T}[\mathrm{K}] 500$ 1000 1500 2000 2500

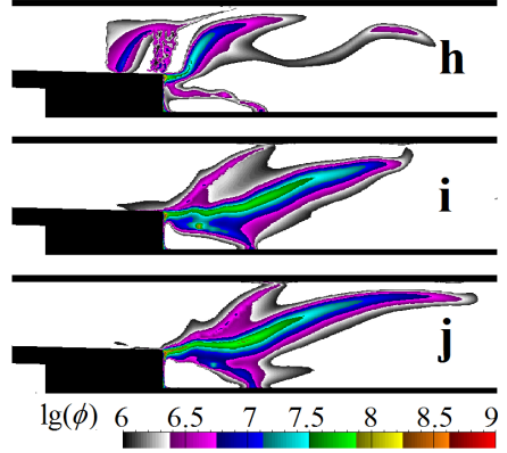

Fig. 8. One oscillation cycle of the flame front in the chamber with a step. The temperature fields $[\mathrm{K}]$ and the field of heat dissipation rate decimal logarithm. The scale in the vertical direction is increased

At the time moment "a", the pseudoshock takes the extreme left position in the isolator. At this moment, $T<900 \mathrm{~K}$ in the inviscid core of the flow near the injectors. Therefore, the combustion begins only in middle of the 
combustion chamber (where $\lg \square>7$ ), and the region upstream is occupied with fresh fuel. But behind the step there is a recirculation zone filled by hot combustion products with a temperature of more than $2500 \mathrm{~K}$. The entry of fresh fuel into this zone leads to an increase of its height. The turbulent diffusion transfers the heat upwards and heats the inviscid core of the flow. Because of these factors, compression waves occur above the recirculation zone and heat up the gas (moment "b"). As a result, at the time moment "c", the flame jumps to the step and spreads quickly to the whole cross-section of the duct (moment "d"). It leads to the duct choking, and the pressure grows several dozen times. This explosion generates strong shock waves moving in both directions from the injectors. The wave moving to the left interacts with the boundary layers, generating a new pseudoshock,. It replaces the old pseudoshock that slowly retreats to the right - see the moments "e", "f". At that, the gas accelerates behind the step, and, everywhere in the inviscid core of the flow, the gas flow in direction from left to right is established. The rarefaction waves interact with the pseudo-shock and weaken its front. The temperature near the injectors drops, and the flame begins to retreat downstream (moments "g", "h"). The zone to the right of the injectors is gradually filled with fresh fuel (moment "i"). At time moment " $\mathrm{j}$ ", the flow returns to its initial state. After that, the same sequence of events repeats cyclically. The same oscillation mechanism has been also observed with the inviscid core temperature of $800 \mathrm{~K}$.

Non-damped quasiperiodic oscillations have been obtained in majority of calculations of the chamber with step: both in flat and in $2.5 \mathrm{D}$ calculations (the latter allow to tale into account the displacement of the boundary layers growing on the side walls of the ducts); on the grid refined 2 times in both directions; with the use of $q-\omega$ and Spalart-Allmaras turbulence models; with the other fuel mass flow rate $(\varphi \approx 0.5)$. It is shown that the stopping of combustion in the recirculation zone behind the step leads to a blowout of combustion in the chamber.

The presented calculations have been performed with the assumption of heat-insulated walls. The red curve in Fig. 9 shows the time-averaged pressure distribution along the top wall of the duct that has been obtained in this calculation. The pressure level in the combustion chamber is well predicted. But the pseudo-shock length is strongly overestimated. It has been assumed that when the pseudo-shock oscillates, the temperature does not have time to equalize across the walls, and the oscillation process is influenced by heat fluxes through the duct walls. Then the simulation of flow in the chamber with solution of $1 \mathrm{D}$ unsteady heat conduction equation in each section of the duct walls has been performed. It has turned out that the duct walls do not have time to warm up during the experiment. One can approximate that the temperature of the isolator walls is constant during the "hot" run. Then a series of 2.5D calculations with a given temperature of the duct walls $T_{W}$ has been performed. For example, Figure 9 shows the time-averaged pressure distributions obtained for $T_{W}=700 \mathrm{~K}$. In this case the the pseudoshock length is essentially less. But, in the constant-area part behind the step, the temperature is in worse correspondence with the experiment, than in the approximation of heat-insulated walls. The curve obtained in calculation with $T_{W}=700 \mathrm{~K}$ in the isolator and with the heat-insulated walls in the combustion chamber is also shown. In this case, the temperature level in the combustion chamber is closer to the experiment, but the pseudo-shock length is higher.

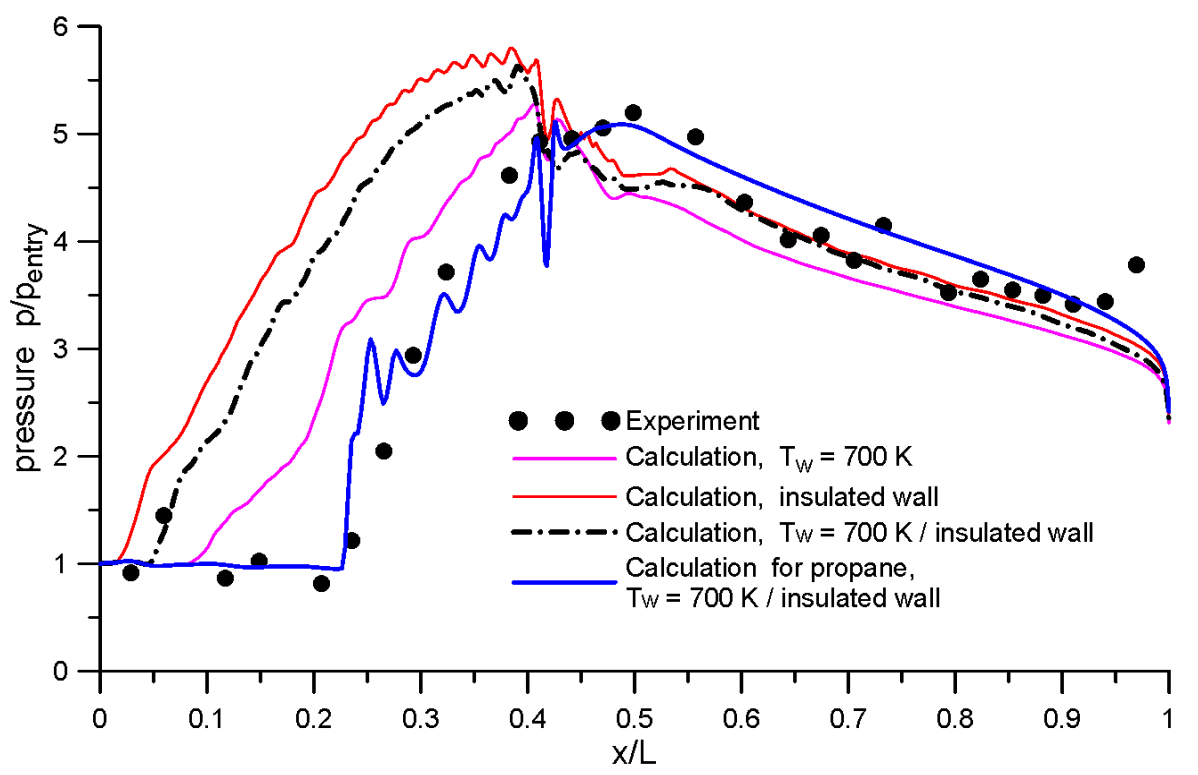

Fig. 9. Pressure distributions along the upper wall of the duct for different models of heat exchange and chemical kinetics ( $\varphi \approx 0.75$ mode) 
None of the described calculations could correctly describe the pressure growth rate in the pseudo-shock. Then the calculations have been performed with the real hydrocarbon fuel replaced by pure propane $\mathrm{C}_{3} \mathrm{H}_{8}$. In these calculations the wall temperature in insulator $T_{W}=700 \mathrm{~K}$ and heat-insulated walls in the combustion chamber were given. As a result, a stationary solution has been achieved without combustion zone oscillations. Combustion was stabilized in a standing wave of deflagration, propagating due to turbulent diffusion of heat. The wave starts from the step corner and is located across the main flow. The wave front is inclined so that the flow velocity projection on the normal to the wave front is equal to the combustion wave velocity relative to gas. In that calculation, the best correspondence of the pressure distributions along the upper wall of the duct with the experiment has been achieved see the blue curve in Fig. 9. Both the pressure growth rate in the pseudoshock and the pressure maximum in the vicinity of the step has been reproduced. Therefore, the kinetic scheme significantly influences on the solution of this class problems.

\section{Studies of turbulent-combustion interaction (TCI)}

An essential problem in turbulent combustion simulation is correct description of chemical processes in the presence of turbulent pulsations. In real combustors, different combustion regimes may occur. Two limiting cases are premixed combustion and non-premixed diffusive combustion. In TsAGI an attempt was undertaken to develop an original combined method that has advantage to treat different combustion regimes without alteration of numerical algorithm $[5,29]$. In the case of premixed combustion, the contribution of turbulent fluctuations into average rates of reactions is neglected and the source terms $\left(\bar{W}_{i}^{\text {lam }}\right)$ are calculated using parameters of time-averaged flow, substituted into usual Arrenius-like formulas ("quasi-laminar approximation"). In the limit of diffusive combustion, the turbulence-combustion interaction (TCI) is taken into account using the method based on presumed probability density function (PDF) together with some variant of flamelet model [30]. It is common practice to use PDF together with flamelet model for direct calculation of flow parameters (mass fractions and temperature), which allows to eliminate equations for the reacting gas components and therefore to reduce computational costs. It should be noted that authors of current study applied PDF method only to calculation of source terms in equations for the reacting gas components - $\bar{W}_{i}$ - if the limit of diffusion combustion is locally realized. TCI account is intended to improve the quality of flow description compared to "quasi-laminar approximation". In this case, simplified version of formula for calculation of $\bar{W}_{i}$ looks as follows:

$$
\bar{W}_{i}^{p d f}=\int_{0}^{1} W_{i}(z) \operatorname{PDF}(z, \bar{z}, \sigma) d z .
$$

where $\mathrm{z}$ is mixing variable that is equal to 1 in pure fuel and to 0 in pure air. PDF function is presumed to be $\beta$ -function with coefficients depending upon $\bar{z}$ and $\sigma=\overline{z^{\prime 2}}$. For $\bar{z}$ and $\sigma$, additional partial differential equations are solved. The dependence $W_{i}(z)$ is taken from solution of differential equation for laminar flamelet [27]. The library of $\bar{W}_{i}^{p d f}$ values is precalculated and tabulated with the parameters set.

The final values of source terms are calculated as a linear combination of $\bar{W}_{i}^{\text {pdf }}$ and $\bar{W}_{i}^{\text {lam }}$. The method takes into account non-equilibrium combustion effects and turbulence intermittency effects.

In general, authors' experience [5, 29] concerning presumed PDF together with flamelet models has revealed a number of critical points. To begin with, it was found that this method is inapplicable if dependence is taken from the stationary limit of the laminar flamelet development. The reason for this is that in the stationary limit the flamelet development is finished and source terms are very small. As a result, in the diffusion combustion region, where ignition must occur, the flame was blown out. To avoid this situation, it is necessary to take into account the transient processes of the unsteady flamelet development, when huge values of source terms appear. To accomplish this, one more variable was added - reaction progress variable $c$. It was taken equal to mass fraction of reaction product.

Further, calculations of test problems using the combined method have revealed very strong dependence of solution upon determination of $\sigma=\overline{z^{\prime 2}}$ that is essential parameter in presumed PDF definition. The value of $\sigma$ is obtained from solution of semi-empirical partial differential equation. In CFD studies of turbulent combustion, this semi-empirical equation is usually verified for round jet configurations and for low Mach numbers. Additional verification and improvement is required for complex flow configurations (high-speed compressible flows, near-wall jets, etc.). Furthermore, this approximate equation may produce the values that do not satisfy to physical constraints. 
It leads to incorrect values of $\bar{W}_{i}^{p d f}$ and to instability of numerical solution. To avoid such situations, it was proposed in [30-28] to impose an additional limitation: $\sigma \leq \sigma_{\max }=c_{\sigma \max } \cdot \min \left\{\bar{z}^{2},(1-\bar{z})^{2}\right\}$. Coefficient $c_{\sigma \max }<1$ should be chosen on the basis of experimental data.

The described limitation eliminated the encountered instability. However it's not the best solution to the problem because it imposes artificial limitations on the flow development. A better solution possibly could be tuning of equation for the value of $\sigma$ but it's beyond the current paper.

For the validation of the combined method, classical experimental data on high-speed turbulent combustion were used, including simulation of Evans-Schexnayder-Beach experiment [31] (combustion in axisymmetric jet), Burrows-Kurkov experiment [32] (combustion in planar near-wall jet). Figure 10 presents two characteristic examples of the validation results - cross-section profiles of the reaction product $\left(\mathrm{H}_{2} \mathrm{O}\right)$ average fraction and their comparison with experiment. Both profiles - obtained with "laminar approximation" with no TCI and profiles obtained using the described combined method with different values of coefficient $c_{\sigma \max }$-are shown.

Figure 10 shows that calculations without TCI account give incorrect positions and amplitude of extremum (in comparison with experiment). Activation of TCI may lead to strong variation of profiles. Nevertheless, the shape of profiles remains to be far from experiment for all values of $c_{\sigma \max }$. It is important to note that the results obtained in the mixing regime without combustion are in good accordance with experiment and calculations of other authors. However, when we turn to combustion, it is not the case.

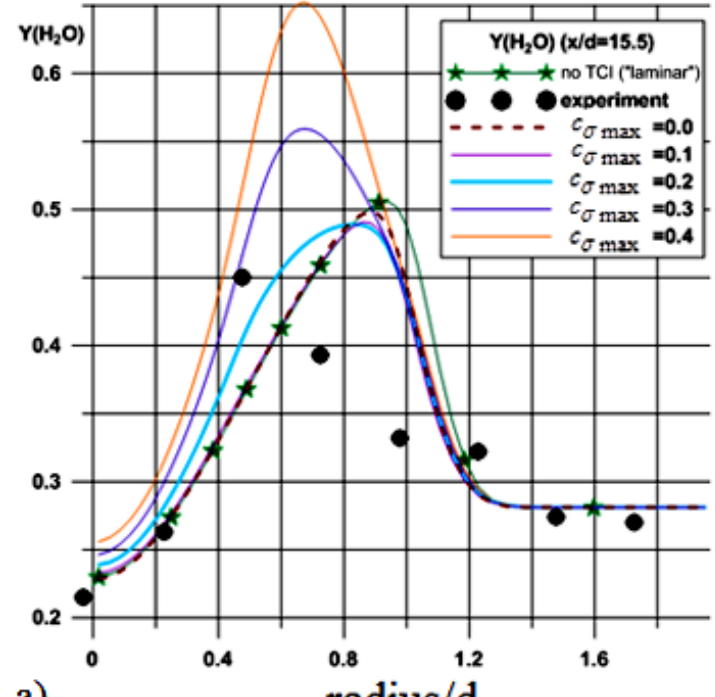

a) radius/d

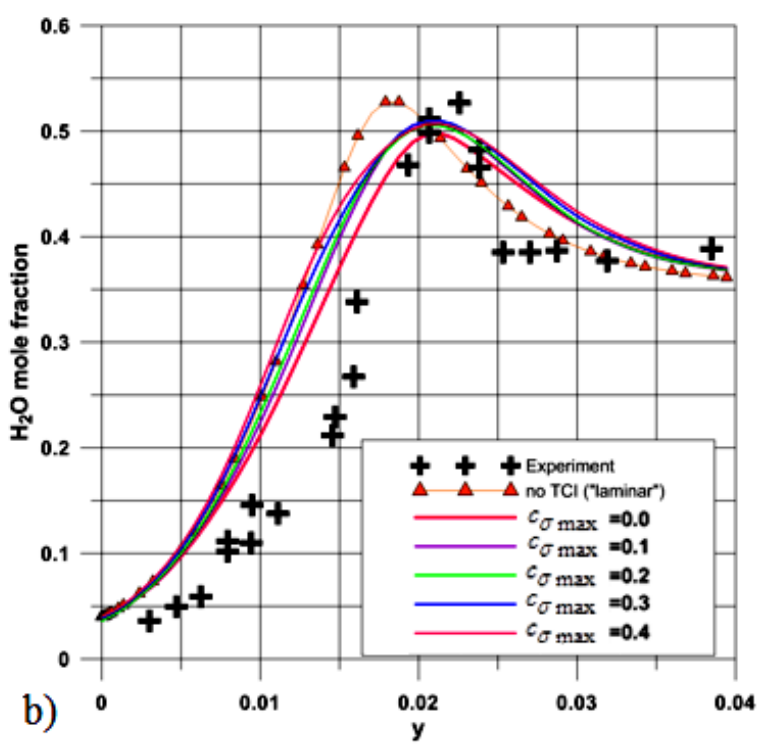

Fig. 10. Profiles of the reaction product in cross sections of turbulent jet with combustion:

a) Beach et al experiment; b) Burrows-Kurkov experiment

Study of the influence of other empirical coefficients of the model (in particular, influence of Prandtl and Schmidt turbulent numbers in equations for $\bar{z}$ and $\sigma=\overline{z^{\prime 2}}$ also has been performed. However, no good agreement with experimental data was obtained. It is quite possible that the results depend also upon correct description of turbulence development, inflowing profiles, upstream influence through the boundary layers and also upon 3D effects.

One of the main drawbacks is that it that the chosen approach for TCI taking into account (based on presumed PDF together with flamelet model) couldn't be applied for the gas flows of practical interest in combustors where the incoming flow is strongly non-uniform and contains partially premixed regions. The weakness of the theory is plenty of supposition, which confine the applicability region to simple configurations. When these assumptions are not fulfilled, these underlying hypotheses produce more errors than improvement in the flow description. All attempts to expand the applicability range of the theory and to take into account various effects lead to multiple additional hypotheses and uncertainties resulting in error accumulation.

This experience shows the necessity of detailed and profound investigations of turbulent combustion in highspeed flows. For this purpose, a Laboratory "Studies and development of physical models and numerical 
technologies for description of combustion regimes in aircraft engines" has been created in TsAGI under the leadership of the leading scientist, Prof. V.A. Sabelnikov (now ONERA adviser, France). This project has been supported by the megagrant of the Ministry of Education and Science (Russian Federation) in the framework of the Decree of the Russian Federation Government of April 9, 2010 No. 220 (contract No. 14. G39.31.0001 of February 13, 2017). The Laboratory will develop and validate models of various combustion regimes in air-breathing engines, as well as create special software to use it in the cycle of aerodynamic design of advanced aircraft power plants.

Majority of TCI models are focused on subsonic flows. In this case the characteristic time of chemical reactions is usually much less than the characteristic time of the flow. It is under these conditions that such methods of the TCI account as the above-described flamelet approach, the Eddy Break-Up model (EBU) [33] and the Eddy Dissipation Concept (EDC) [34] are well justified and give good results. The main peculiarity of high-speed flows is that the characteristic time of chemical reactions becomes comparable with the characteristic time of the flow. Significant ideas to describe the combustion under these conditions were formulated by E.S. Schetinkov [35] and by L.A.Vulis [36]. In fact, these ideas were implemented in models of Partially Stirred Reactor (PaSR) [37]. In recent years this approach has been developed in the works by V.A.Sabelnikov [38-39], and it is this direction of TCI modeling that is selected as the primary for the new Laboratory.

\section{Choice of geometry and flow regimes for model combustor on propane}

An essential element of the works in Laboratory "Studies and development of physical models and numerical technologies for description of combustion regimes in aircraft engines" will be the validation of the created physical models and software on the basis of a "fire" aerodynamic experiments, specially performed in TsAGI. For this purpose, an experimental model of a dual-mode combustion chamber (a chamber with supersonic flow at the entrance, where a subsonic or supersonic combustion regime is realized depending on the inflow parameters) has been recently designed. It will be manufactured and tested at T-131 wind tunnel in the regime of the connecting pipe.

In design of the combustion chamber, ONERA experience of investigating a model chamber of similar geometry has been taken into account. This chamber has been studied at the ONERA-LAERTE test rig in the framework of LAPCAT-II European project [40]. In these experiments, ONERA received both subsonic combustion with a pseudoshock and different supersonic combustion regimes, characterized by the interaction between fuel jets injected from the walls, boundary layers on the chamber walls and shock-wave structures in the duct.

The geometry of the combustion chamber (Fig. 11) was designed with taking into account the experience of investigations of high-speed combustion chambers in T-131 WT (TsAGI). The flow regime with the total parameters $P_{\mathrm{t}}=1 \mathrm{~atm}, \underline{T}_{\mathrm{t}}=2100 \mathrm{~K}$ and Mach number at the chamber entrance $M=2.5$ was chosen. For this regime, the static temperature in the inviscid core of the flow at the chamber entrance is close to $1030 \mathrm{~K}$. The lateral width of the chamber is constant and equal to $0.1 \mathrm{~m}$. In the side walls of the chamber, 4 pairs of optical windows manufactured of quartz glass (thickness is $0.05 \mathrm{~m}$ ) will be mounted. Propane $\mathrm{C}_{3} \mathrm{H}_{8}$ is chosen to be a fuel as a simplest pure analogue of modern aviation hydrocarbon fuels. It will be injected through two pairs of holes located at the upper and lower walls of the chamber before the isolator end, perpendicular to the walls (Fig. 11). At the end of the constant crosssection part, a pneumothrottle will be mounted on the bottom wall before the nozzle beginning. As well as in the ONERA experiments, a wide range of measurements is planned for registration of the flow physical picture: high-speed Schlieren-video; visualization of the excited OH radical radiation (that allows to determine the position of the heat-release zones); wall temperature measurement by thermocouples mounted inside the chamber walls and on its outer surface; measurements of both time-averaged pressure values and pressure oscillations.

In order to choose the fuel injection schemes that will provide both the subsonic and the supersonic combustion regimes in the duct, preliminary calculations have been performed on the basis of unsteady RANS equations for a multi-component gas with finite-rate reactions in the $2.5 \mathrm{D}$ approximation. The calculations have shown that propane self-ignition does not occur with the chosen flow regime and, in the case of pneumothrottle using, the combustion blows out after the throttle is turned off.

To provide the combustion stabilization, it has been decided to mix hydrogen to propane. Hydrogen is more energy-intensive fuel and much more easily ignited. In the case of an fuel excess ratio $\varphi=0.67$ with addition of $15 \%$ $\mathrm{H}_{2}$, a stationary asymmetric flow with subsonic combustion is obtained - see the fields of temperature and Mach numbers in Fig. 12,a and in Fig. 13,a. The separation before the jet of the upper injector plays the role of the flame stabilizer. The red curve in Fig. 14 shows the longitudinal distribution of the Mach number averaged by the momentum flux over the duct cross-sections.

On may see that the flow becomes subsonic on average at a part of constant cross-section after a series of oscillations. It is clear now that the flow zone at the part $0.15 \mathrm{~m}<x<1.35 \mathrm{~m}$ contains shock-wave structures interacting with the boundary layers, where the transition from supersonic to subsonic flow takes place. According to these features, this flow zone can be categorized as a pseudoshock.

Page 16 of 20 


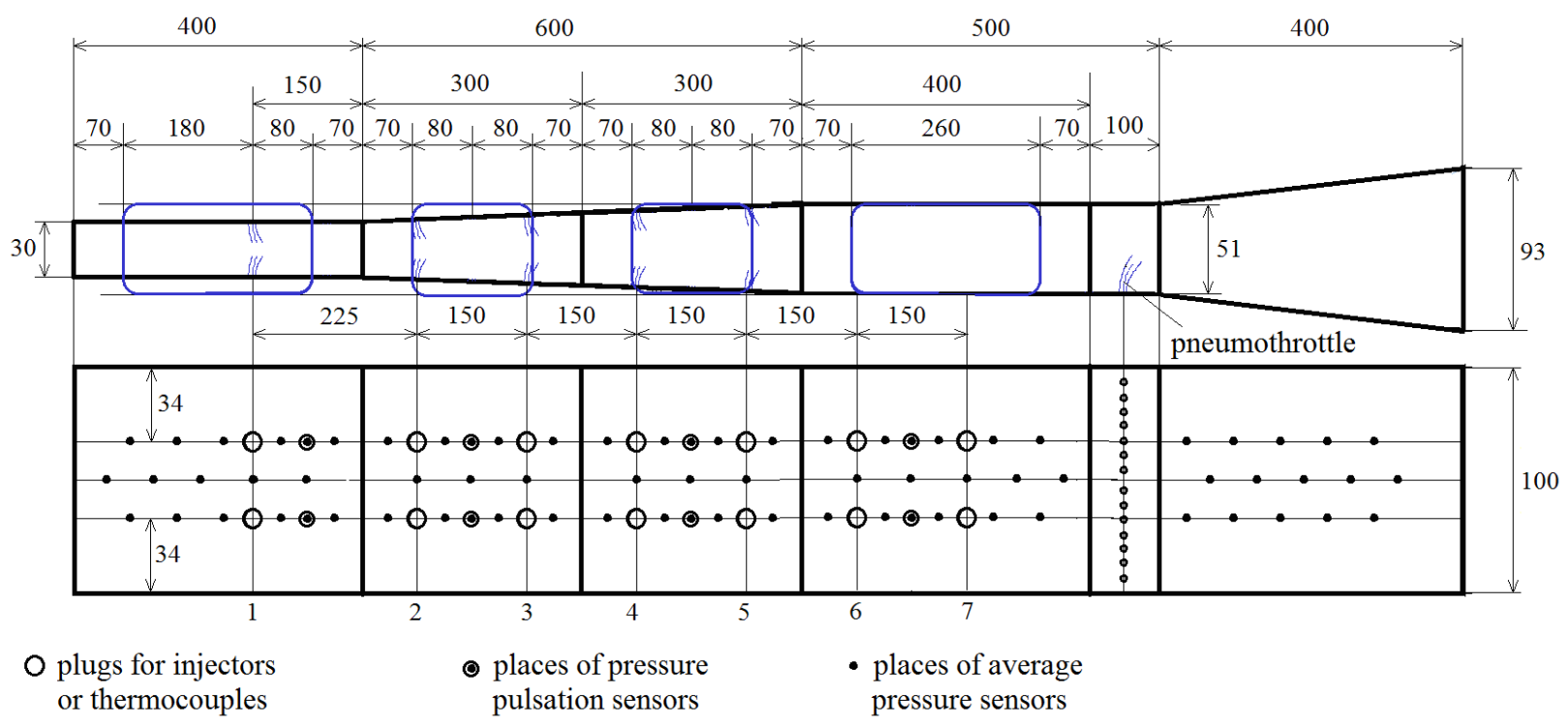

Fig. 11. Sketch of model combustor geometry with places of measurements.

Lengths in millimeters. Blue rectangles - positions of optical windows

It is interesting that this flow structure is asymmetric, though the duct geometry and computational grid are symmetric (except truncations errors). During the flow development, the fuel enters the separations upstream from the injector jets, and because of combustion the size of the separations increases. Because of small perturbations, the first portion of the fuel, which got into the separations, burns off at the lower wall earlier than at the upper. Introducing the small perturbations into the flow development made it possible to obtain the same asymmetric structure of the flow, but with separation near the lower wall of the duct (Fig. 12,b). If one imposes symmetry of the flow, calculating only one half of the duct, then a quasi-stationary regime of combustion with weak longitudinal oscillations of the flame is realized (two moments of these oscillations are shown in Fig. 12,c,d). The oscillations are produced by a periodic stop and the renewal of combustion in separations upstream from the fuel jets.

At $\varphi=0.33$, with the addition of $30 \% \mathrm{H}_{2}$, a stationary symmetric flow with supersonic combustion near the chamber walls has been obtained - see Fig. 12,e and Fig. 13,b. The combustion proceeds mainly in supersonic regime in the boundary layers on the expanding part of the duct. As the blue curve in Fig. 14 shows, the Mach number averaged over cross-sections remains supersonic along the entire length of the duct.

\section{Acknowledgements}

The work, described in Section 4, is performed within the 'High-Speed Experimental Fly Vehicles-International' project fostering International Cooperation on Civil High-Speed Air Transport Research. HEXAFLY-INT, coordinated by ESA-ESTEC, is supported by the EU within the 7th Framework Programme Theme 7 Transport, Contract no.: ACP0-GA-2014-620327. Further info on HEXAFLY-INT can be found on http://www.esa.int/hexaflyint. Results, presented in Section 7, are supported by Grant of the Ministry of Education and Science of Russian Federation (agreement No.14.G39.31.0001). 


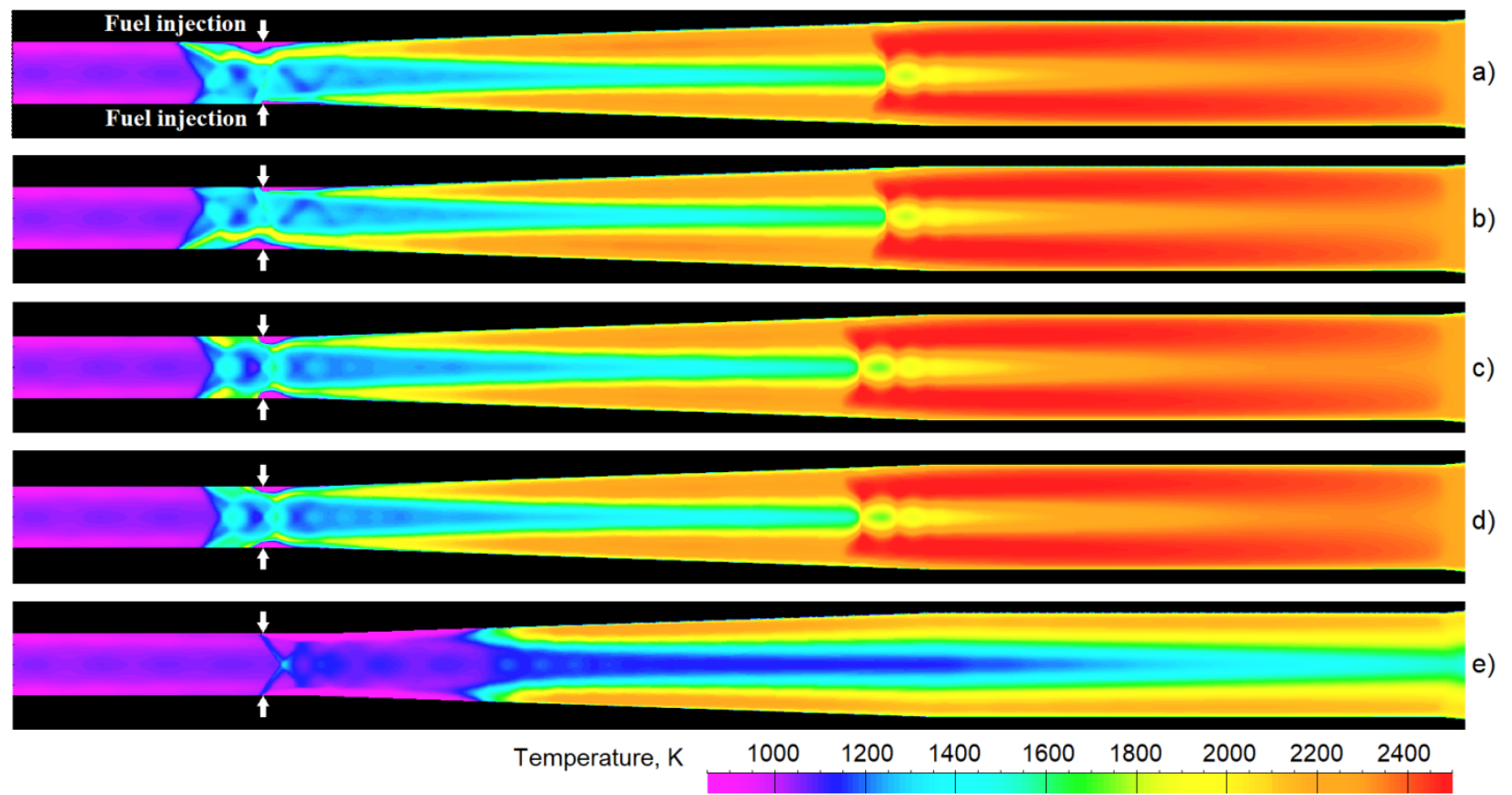

Fig. 12. The fields of temperature [K] in the calculations for $\varphi=0.67$ with the addition of $15 \%$ hydrogen (a-d) and for $\varphi=0.33$ with the addition of $30 \%$ hydrogen (e). c,d - two moments of oscillatory regime obtained with condition of the flow symmetry

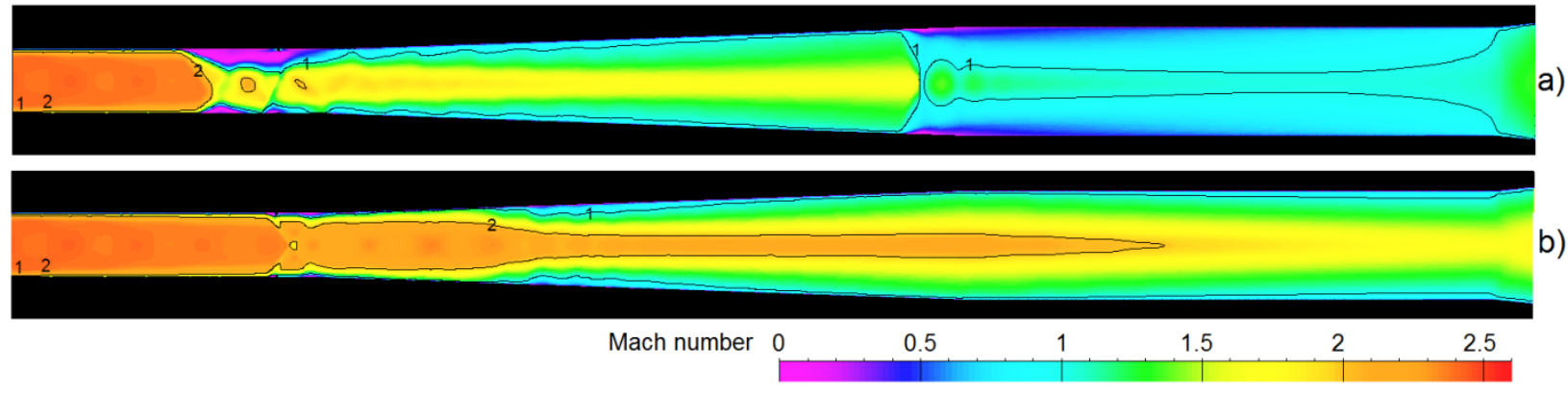

Fig. 13. The fields of Mach number in the calculations for $\varphi=0.67$ with the addition of $15 \%$ hydrogen (a) and for $\varphi=0.33$ with the addition of $30 \%$ hydrogen (b)

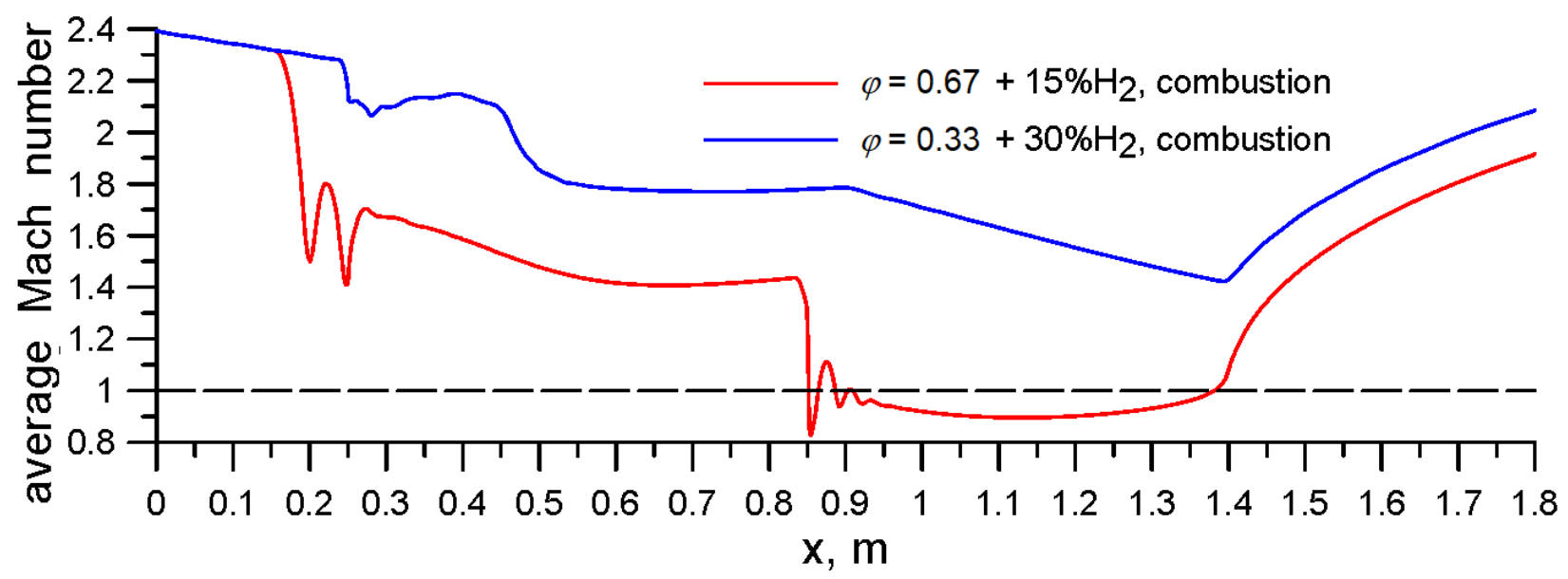

Fig. 14. Longitudinal distributions of the Mach number averaged over the cross-sections 


\section{References}

[1] R. Keller, M. Lempke, Y. H. Simsont, P. Gerlinger, M. Aigner, Parallelization and performance analysis of an implicit compressible combustion code for aerospace applications, High Performance Computing in Science and Engineering '14 . Springer International Publishing, 2015, 251-266.

[2] S. Vo, A. Kronenburg, O. T. Stein, E.R. Hawkes, Direct numerical simulation of non-premixed syngas combustion using OpenFOAM, High Performance Computing in Science and Engineering'16. Springer, Cham, 2016, 245-257.

[3] T. Weydahl, M. Poyyapakkam, M. Seljeskog, N. E. L. Haugen, Assessment of existing $\mathrm{H}_{2} / \mathrm{O}_{2}$ chemical reaction mechanisms at reheat gas turbine conditions, Int. Journal of Hydrogen Energy, Vol.36, No.18 (2011), 12025-12034.

[4] A. Rebola, P. J. Coelho, M. Costa, Assessment of the performance of several turbulence and combustion models in the numerical simulation of a flameless combustor, Comb. Science and Technology, Vol.185, No.4 (2013), 600-626.

[5] A. Shiryaeva, V. Vlasenko, K. Anisimov, Development and application of numerical technology for simulation of different combustion types in high-speed viscous gas turbulent flows, 44th AIAA Fluid Dynamics Conference, 2014, 2097.

[6] V. V. Vlasenko, A. A. Shiryaeva, Application of the fast calculation technologies to simulation of nonstationary supersonic viscid flow with combustion, 28th Congress of the International Council of the Aeronautical Sciences 2012 (ICAS 2012), Brisbane (Australia), 2012, 10 pages.

[7] A.A. Babulin, S.M. Bosnyakov, V.V. Vlasenko, M.F. Engulatova, S.V. Matyash, S.V. Mikhailov, Experience of validation and tuning of turbulence models as applied to the problem of boundary layer separation on a finite-width wedge, Comp. Mathematics and Mathematical Physics, Vol.56, No.6 (2016), 1020-1033.

[8] V.V. Vlasenko, A.A. Shiryaeva, Computations of flow in a model high-speed combustor using different kinetic schemes, Combustion and explosion, Vol.8, No.1 (2015), 116-125. (In Russian.)

[9] V.Ya. Basevich, S.M. Frolov, Global kinetic mechanisms for simulation of multi-stage self-ignition of hydrocarbons in reactive flows, Russian Journal of Chemical Physics, Vol.25, No.6 (2006), 54-62.

[10] V. V. Vlasenko, Numerical simulation of the unsteady propagation of combustion in a duct with a supersonic viscous gas flow, Russian Journal of Physical Chemistry B, Vol.5, No.5 (2011), pp. 800-812.

[11] M. M. Pervaiz, J. R. Baron, Spatiotemporal adaptation algorithm for two-dimensional reacting flows, AIAA Journal, Vol.27, No.10 (1989), 1368-1376.

[12] S. Bosnyakov, I. Kursakov, A. Lysenkov, S. Matyash, S. Mikhailov, V. Vlasenko, Computational tools for supporting the testing of civil aircraft configurations in wind tunnels, Progress in Aerospace Sciences, Vol. 44 (2008), 67-120.

[13] B. E. Launder, D. B. Spalding, The numerical computation of turbulent flows, Computer methods in applied mechanics and engineering, Vol.3, No.2 (1974), 269-289.

[14] E. Goncalves, R. Houdeville, Reassessment of the wall functions approach for RANS computations, Aerospace Science and Technology, Vol.5, No.1 (2001), 1-14.

[15] R. H. Nichols, C. C. Nelson, Wall function boundary conditions including heat transfer and compressibility, AIAA journal, Vol.42, No.6 (2004), 1107-1114.

[16] V. V. Vlasenko, and A. A. Shiryaeva, 2.5D approximation for numerical simulation of flows in engine ducts, 6th European Conference for Aeronautics and Space Sciences (EUCASS 2015), Kraków (Poland), 29 June - 3 July, 2015, 14 pages. Full text is available for participants at http://www.eucass2015.eu/detailed-programme/. Selected for publication in EUCASS 2015 Propulsion Physics Volume.

[17] V. Sabel'nikov, O. Voloshenko, V. Ostras, V. Sermanov, R. Walther, Gasdynamics of hydrogen-fueled scramjet combustors, 29th Joint Propulsion Conference and Exhibit. 1993, 2145.

[18] R. Walther, V. Sabelnikov, Y. Korontsvit, O. Voloschenko, V. Ostras, V. Sermanov, Progress in the joint german-russian scramjet technology programme, ISABE Paper 95-7121, 1995, 15 pages.

[19] M. Ivankin, A. Nikolaev, V. Talyzin, O. Voloschenko, Experimental investigations of the hydrogen combustion chamber for high-speed vehicle, 20th AIAA International Space Planes and Hypersonic Systems and Technologies Conference., 2015, 3617.

[20] V. A. Talyzin, V. V. Vlasenko, O. V. Voloschenko, M. A. Ivankin, Experimental and $2.5 \mathrm{D}$ numerical investigation of the high-speed combustion chamber within the international HEXAFLY-INT project, 21st AIAA International Space Planes and Hypersonics Technologies Conference, 2017, 2326.

[21] G. F. Glotov, N. V. Gurilyova, M. A. Ivankin, Gasthermodynamics of flows in model ducts of scramjets, ISABE Paper 99-7054, 1999, 15 pages. 
[22] N.Kh. Remeev, V.V. Vlasenko, R.A. Khakimov, Numerical and experimental investigation of detonation initiation in a cylindrical duct, Deflagrative and detonative combustion, Ed. by G. Roy and S. Frolov, Moscow, Torus Press, 2010, 313-328.

[23] N.Kh. Remeev, V.V. Vlasenko, R.A. Khakimov, L. Serre, Experimental study and numerical modelling of detonation damping in a duct, Deflagrative and detonative combustion. Ed. by G. Roy and S. Frolov, Moscow, Torus Press, 2010, 329-346.

[24] T. Langener, J. Steelant, S. Karl, K. Hannemann, Design and Optimization of a Small Scale M=8 Scramjet Propulsion System, Space Propulsion 2012, Bordeaux: AAAF/ESA/CNES.

[25] T. Langener, J. Steelant, S. Karl, K. Hannemann, Layout, Design, Verification of a Small Scale Scramjet Combustion Chamber, ISABE 2013, Busan, Korea, 1655.

[26] Y. V. Zeldovich, U. A. Zisin, On the theory of thermal stress, Flow in an exothermic stirred reactor, I. J. Tech. Phys, 11(6), 1941, 493-500.

[27]D. S. Cohen, Multiple stable solutions of nonlinear boundary value problems arising in chemical reactor theory, SIAM Journal on Applied Mathematics, 20(1), 1971, 1-13.

[28] V. V. Vlasenko, About different ways to determine the heat effect and the combustion efficiency in a flow of reacting gas, TsAGI Science Journal, Vol.45, No.1 (2014), 35-59.

[29] A. Shiryaeva, K. Anisimov, Development and application of numerical technology for simulation of different combustion types in high-speed viscous gas turbulent flows, 6th European Conference for Aeronautics and Space Sciences (EUCASS 2015), Kraków (Poland), 29 June - 3 July, 2015, 14 pages. Full text is available for participants at http://www.eucass2015.eu/detailed-programme/.

[30] N. Peters, Laminar flamelet concepts in turbulent combustion, Symposium (International) on Combustion, Elsevier, Vol.21, No.1, 1988, 1231-1250.

[31] J. S. Evans, C. J.Schexnayder, H. L. Beach, Application of a two-dimensional parabolic computer program to prediction of turbulent reacting flows, NASA TP-1169, 1978.

[32] M. C. Burrows, A. P. Kurkov, Analytical and Experimental Study of Supersonic Combustion of Hydrogen in a Vitiated Air Stream, NASA TM X-2828, 1973.

[33] D. B. Spalding, Mixing and chemical reaction in steady confined turbulent flames In: Symposium (International) on Combustion, Elsevier, Vol.13, No.1, 1971, 649-657.

[34] B. F. Magnussen, The Eddy Dissipation Concept - A Bridge Between Science and Technology, ECCOMAS thematic conference on computational combustion, 2005, 24 pages.

[35] E. S. Schetinkov, Calculation of flame velocity in turbulent stream, Symposium (International) on Combustion, Vol.7, 1958, 583-589.

[36] L. A. Vulis, The Thermal Combustion Regime, Moscow-Leningrad, Gostekhizdat, 1954, 288 pages (In Russian).

[37] J. Chomiak, A. Karlsson, Flame liftoff in diesel sprays, Symposium (International) on Combustion, Elsevier, Vol. 26, No. 2, 1996, 2557-2564.

[38] V. Sabelnikov, C. Fureby, Extended LES-PaSR model for simulation of turbulent combustion, Progress in Propulsion Physics, Vol.4 (2013), 539-568.

[39] Y. Moule, V. Sabelnikov, A. Mura, Highly resolved numerical simulation of combustion in supersonic hydrogen-air coflowing jets, Combustion and Flame, Vol.161 (2014), 2647-2668.

[40] A. Vincent-Randonnier, Y. Moule, M. Ferrier, Combustion of hydrogen in hot air flows within LAPCAT-II dual mode ramjet combustor at ONERA-LAERTE facility - experimental and numerical investigation, 19th AIAA International Space Planes and Hypersonic Systems and Technologies Conference, 2014, 2932. 